\title{
La exploración del litoral atlántico norteafricano según el periplo de Hannón de Cartago
}

\author{
Alfredo Mederos Martín \\ Universidad Autónoma de Madrid \\ alfredo.mederos@uam.es
}

Recibido: 16 de octubre de 2014

Aceptado: 15 de mayo de 2015

\section{RESUMEN}

El periplo de Hannón, frente a las propuestas que lo interpretan como una obra literaria, creemos que recoge un periplo auténtico, que sólo alcanzó cabo Juby y algunas de las Islas Canarias. Las refundaciones cartaginesas fueron todas en la Mauretania fértil, en los 7 primeros días de la expedición. Desde el islote de Kérne, en la expedición primó una primera exploración de evaluación, indicativo de que se trataba de apenas 2 o 3 barcos, con una tripulación limitada, que evitaban enfrentamientos con la población local. Los intérpretes Lixitai parecen conocer todos los puntos explorados, el río Chrétes, los etíopes del Alto Atlas costero, el gran golfo caluroso que finalizaba en el Hespérou Kéras, el volcán Theôn Óchema, o las gentes salvajes que denominaban Gorillai. Probablemente la mayor sorpresa fuese encontrar un volcán activo, emitiendo lava, que pudo ser la razón última para redactar este periplo. La falta de agua, alimentos y caza como razón para finalizar la expedición exploratoria sólo es comprensible en un trayecto corto que alcanzó hasta el inicio del desierto del Sahara. Otro tanto sucede con la ausencia de ríos importantes al Sur del río Chrétes, una clara prueba de que no se alcanzaron latitudes ecuatoriales y que los barcos se fueron alejando de la costa norteafricana.

Palabras clave: Periplo. Norte de África. Hannón. Cartago.

\section{The Exploration of the North African Atlantic Coast According to the Periplus of Hanno of Carthage}

\begin{abstract}
The Periplus of Hanno, against the proposals that interpret it as a literary work, we believe that reflects a real voyage, which only reached Cape Juby and some of the Canary Islands. The Carthaginian new foundations were all in fertile Mauretania, in the first 7 days of the expedition. From the island of Kérne, took priority a first exploration of evaluation, indicating that it was just 2 or 3 ships with a limited crew, who avoided confrontations with the local population. The interpreters Lixitai knew all the regions explored: the river Chrétes, the Ethiopians of the coastal High Atlas, the great warm Gulf that ended in Hespérou Kéras, the volcano Theôn Óchema, or the savage people which they called Gorillai. Probably the biggest surprise was to find an active volcano, emitting lava, which could be the ultimate reason for writing the Periplus. The lack of water, food and hunting as reason to finish the exploratory expedition
\end{abstract}


is only understandable in a short voyage that reached up the beginning of the Sahara desert. The same applies to the absence of major rivers south of the river Chrétes, a clear proof that no equatorial latitudes were reached and the ships were away from the North African coast.

Key words: Periplus. North Africa. Hanno. Carthage.

Sumario: 1. Introducción. 2. Las primeras refundaciones de ciudades en el periplo. 3. La isla de Kérne y la fundación de puntos de escala. 4. El problema del río Chrétes. 5. El gran golfo que finaliza en el Cuerno del Oeste. 6. La clave del gran volcán. 7. La isla de las "gentes salvajes" denominadas gorilas. 8. Conclusiones.

\section{Introducción ${ }^{1}$}

A la hora de valorar el Periplo de Hannón ${ }^{2}$ tres son los principales elementos de discusión, aparte del problema de su transmisión textual. El primer punto es la división entre los que plantean que debe tratarse de un periplo auténtico y quienes lo consideran una obra literaria de ficción. El segundo tema de debate es entre quienes aceptando su veracidad, discuten si se trató de un trayecto largo que alcanzó hasta latitudes ecuatoriales o bien fue un viaje que no sobrepasó el cabo Juby y las Islas Canarias en el inicio del Sahara. El tercer gran elemento de discusión es la cronología del periplo y el momento que refleja dentro de la historia de Cartago. Será en el segundo gran tema de debate, la distancia recorrida, en el que nos centraremos en este trabajo.

Como se trata de un periplo que ha sido objeto de notables estudios, los cuales han continuado en los últimos años, ${ }^{3}$ indicativo del interés que despierta especialmente entre los investigadores del ámbito fenicio-púnico, al que ya aportamos una primera valoración global, ${ }^{4}$ pretendemos aquí centrarnos en el segundo aspecto del debate, para ofrecer una defensa del trayecto corto por el litoral atlántico marroquí y las Islas Canarias y enfatizar sus características "realistas" frente a los elementos "míticos" que creemos se han sobrevalorado.

Respecto al primer punto, puesto que se trata de un manuscrito medieval de los siglos IX o X d.C., Codex Palatinus Heidelbergensis Graecus 398, ff. 55r-56r, cabe presumir interpolaciones y alteraciones fruto de sucesivas copias, por lo que difícilmente puede tratarse de un documento oficial o inscripción literalmente transcrita. La

1 Este trabajo, redactado a lo largo de varios años, está dedicado - por sus 85 años- a E. Lipinski, quien ha sido, además, el principal defensor de un trayecto corto del periplo de Hannón y de su final en el entorno del sur de Marruecos y las Islas Canarias. Se adscribe al proyecto HAR2014-53350-P, Utica fenicio-púnica. Urbanismo y economía durante el I milenio a.C., Ministerio de Educación y Ciencia, bajo la dirección de J. L. López Castro. Queremos agradecer la revisión del texto a A. M Canto.

2 Seguiremos la edición crítica del texto al castellano de GonZÁlez Ponce 2008, 116-151; ID. 2011, FGrHist V, Hanno von Karthago (2208), contrastada con las traducciones de GARCía MorENo - GómEz EsPelosín 1996, 113-121 y Schrader 1987; ID. 1990, 99-106. En inglés, las de OiKonomides 1977, 24-28, BlomQvist 1979-80, 59-61 y LIPINSKI 2004, 438-443.

3 Medas 2003; ID. 2006; Lipinski 2004; Díaz del Río 2005; Roller 2006; Desanges 2006; GonzÁlez Ponce 2003-07; ID. 2008; ID. 2010; ID. 2011; López Pardo 2009; Domínguez Monedero 2009; ID. 2010.

4 Mederos - Escribano 2000. 


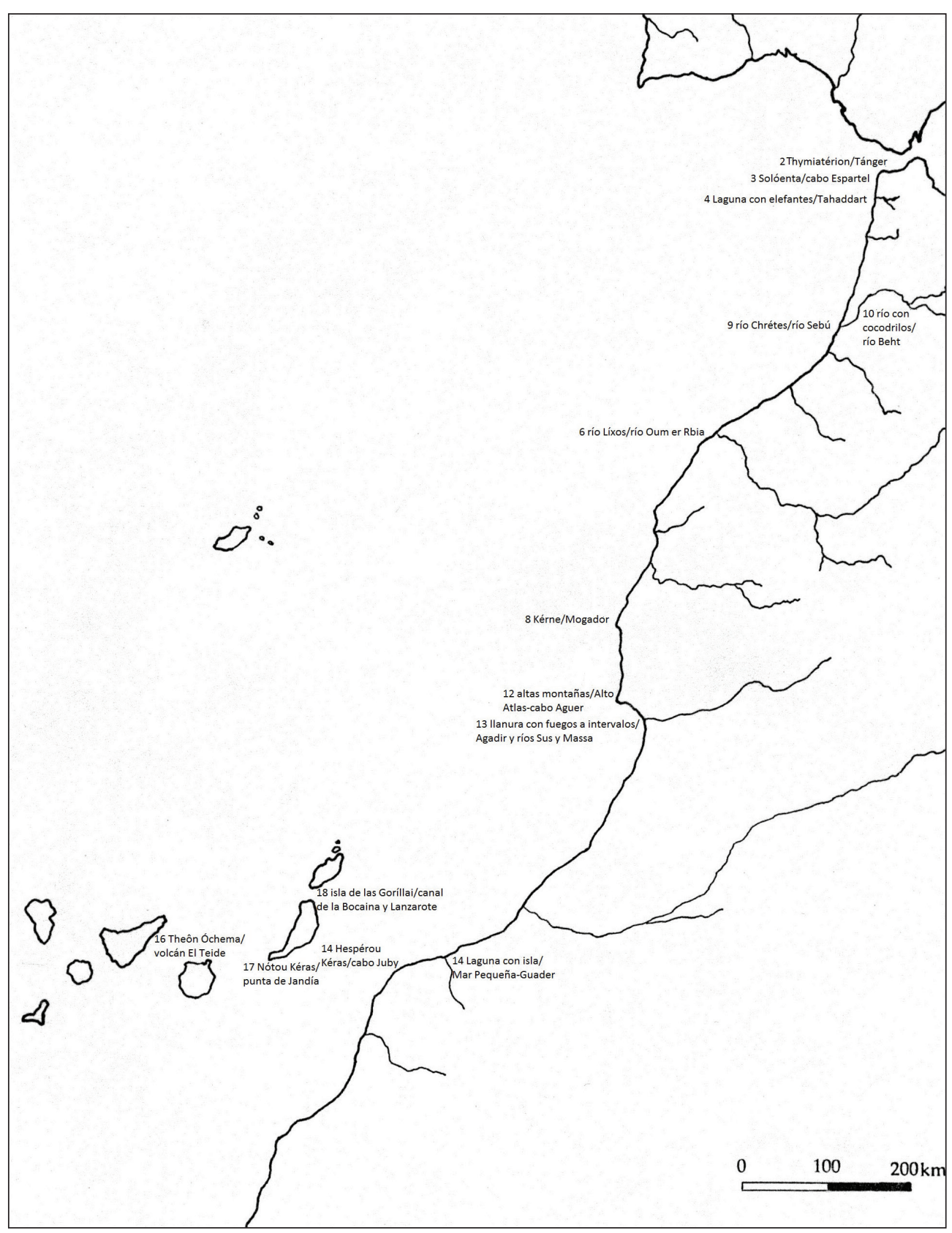

Fig. 1. Propuesta de escalas realizadas en el periplo de Hannón de Cartago. 
Anábasis $^{5}$ también aporta datos adicionales, como la duración de 35 días del viaje, por lo que el texto conservado no está completo, y lo más probable es que hubiera varios resúmenes del viaje, algunos de los cuales pudieron tener un carácter literario y remontarse a los siglos II y I a.C., ${ }^{6}$ lo cual confirman las propias fuentes: "Jenofonte de Lámpsaco nos ha transmitido que el general cartaginés Hannón desembarcó en estas islas" o "Existieron también unos comentarios de Hannón, jefe cartaginés, a quien, durante el máximo esplendor del imperio púnico, se le ordenó explorar el contorno de África", ${ }^{8}$ quizás redactados por Juba II.

En relación con la distancia recorrida, los trayectos largos arrancan de los trabajos de Ramusio ${ }^{9}$ y Bougainville, ${ }^{10}$ quienes se apoyan en la capacidad náutica de los siglos XVI y XVII para hacer los cálculos de distancia de días navegados, presuponiendo que sería la misma en época cartaginesa y obviando que la navegación de exploración costeando es siempre mucho más lenta. Así, Bougainville ${ }^{11}$ lo justifica con la expedición portuguesa de 1641, enviada desde Lisboa a San Jorge de la Mina (Ghana), que tardó 12 días hasta la bahía e isla de Arguin (Mauritania), y 26 días entre Arguin y el cabo de Tres Puntos (Ghana), descubierto desde 1471.

Respecto a la cronología de cuando pudo realizarse el periplo hay tres grandes bandas temporales. En general, un grupo de autores oscila entre la victoria sobre los foceos en Alalia (Córcega) el 535 a.C. y la derrota ante Gelón de Siracusa el 480 a.C. en Himera (Sicilia), defendiéndose a veces genéricamente el s. VI a.C., ${ }^{12}$ pero más frecuentemente se opta por finales del VI a.C., ${ }^{13} 550-490$ a.C., ${ }^{14} 530-500$ a.C., ${ }^{15}$ inicios del s. V a.C. ${ }^{16} \mathrm{o}$ antes del 480 a.C. ${ }^{17}$ Un segundo grupo opta por la expansión territorial de Cartago, entre mediados y finales del s. V a.C., cuando Hannón, uno de los tres hijos de Amílcar, que había muerto en Himera, alcanzaría el gobierno de Cartago

\footnotetext{
5 Arrian., Ind., VIII, 43, 11-12. Para esta obra se ha consultado la edición de Gredos (nº 50, 1982, trad. de A. Guzmán Guerra) y The Loeb Classical Library (vol. II, libros V-VII, 1983, editado por P. A. Brunt).

6 Desanges 1978, 83-85; García Moreno - Gómez Espelosín 1996, 101-109; López Pardo 2000, 63-64; Medas 2004, 135-138; GonzÁlez Ponce 2008, 86-91, 110-114; ID. 2010, 777, n. 181.

7 Solin. Coll. Re. Mem. 56, 12; GonzÁlez Ponce 2003-07. Para esta obra se ha empleado la edición de Gredos (nº 291, 2001, trad. de F. J. Fernández Nieto) y la de Th. Mommsen 1895/1956.

8 Plin., NH, V, 1, 8 (se han consultado las ediciones de Gredos [n ${ }^{\circ}$ 206, libros I-II, 1995, trad. de $\mathrm{M}^{\mathrm{a}} \mathrm{L}$. Arribas y A. Ma Moure; $n^{\circ}$ 250, libros III-VI, 1998, trad. de A. Fontán, I. García Arribas y E. del Barrio Sanz; nº 308, libros VII-XI, 2003, trad. de E. del Barrio, I. García Arribas, A. Ma Moure, L. A. Hernández y Mª L. Arribas Hernáez; nº 388, libros XII-XVI, 2010, trad. de F. Manzanedo, I. García Arribas, Mª L. Arribas, A. M Moure y J. L. Sancho], Fontes Hispaniae Antiquae (vol. VII, 113-180, 1987, editado por V. Bejarano], Teubner [libros I-VI, 1906, editado por C. Mayhoff], Les Belles Lettres [libros V, 1-46, 1980, editado por J. Desanges] y The Loeb Classical Library [vol. I, libros I-II, vol. II, libros III-VII, vol. III, libros VIII-XI, vol. IV, libros XII-XVI, 1971, editado por H. Rackham]).

9 Ramusio 1550, 121-124.

10 Bougainville 1759.

11 Bougainville 1759, 20-21.

12 Domínguez Monedero 2009, 283; ID. 2010, 81.

13 Domínguez Monedero 1987, 130; Rebuffat 2001, 26.

14 López Pardo 1991, 62.

15 Huss 1990/1993, 48.

16 Roller 2006, 116.

17 Moffitt 1990, 253; Alvar 1999, 368.
} 
entre el 480-440 a.C. Entre ellos se menciona un genérico s. V a.C., ${ }^{18}$ 510-450 a.C., ${ }^{19}$ 460 a.C., ${ }^{20} 450$ a.C. ${ }^{21}$ o 425 a.C. ${ }^{22}$ La tercera banda temporal suele situarse después del 348 a.C., tras el segundo tratado entre Roma y Cartago y el 264 a.C., antes del inicio de la Segunda Guerra Púnica, 348-300 a.C., ${ }^{23} 348-290$ a.C. ${ }^{24}$ 348-264 a.C. ${ }^{25}$ Actualmente nosotros preferimos un momento justo después de la firma del tratado de Cartago con Roma el 306 a.C., para la reafirmación y consolidación de control púnico de las rutas comerciales en el litoral atlántico ibérico (periplo de Himilcón) y africano (periplo de Hannón). ${ }^{26}$

\section{Las primeras refundaciones de ciudades en el periplo}

El texto comienza con la interpolación del primer párrafo, que se sale del discurso habitual de un periplo exploratorio descriptivo de una región desconocida, donde se menciona a Hannón como rey o basiléus. La identificación étnica de los colonos como libiofenicios. La participación de una cifra muy elevada de colonos, treinta mil. La atípica intervención tanto de hombres como de mujeres. La importancia de la flota desplazada, sesenta embarcaciones, y el tipo de barco empleado, pentecontoros de cincuenta remos. Ninguno de estos datos vuelve a aparecer en el resto del texto. ${ }^{27}$

A partir del segundo párrafo el relato tiene las habituales caracteristicas de un periplo, mencionando la primera fundación de la expedición en la ciudad de Thymiatérion (Peripl. 2), que ya fue identificada con Tánger por Gossellin, ${ }^{28}$ uno de los primeros autores en defender un trayecto corto, y ha sido ampliamente aceptada en los últimos años. ${ }^{29}$ Nos parece la opción más razonable, aunque también se ha sugerido la propia ciudad de Lixus. ${ }^{30}$ La alternativa a esta localización suele ser Mehedia en el río Sebú desde Tissot, ${ }^{31}$ que sigue teniendo partidarios. ${ }^{32}$ La distancia de 2 días en atravesar el estrecho (Peripl. 2), si no hubo escala en Gadir, implicaría un primer día recorriendo el trayecto entre Ceuta-Septem y el río el-Liam, ${ }^{33}$ para alcanzar el segundo día Tánger.

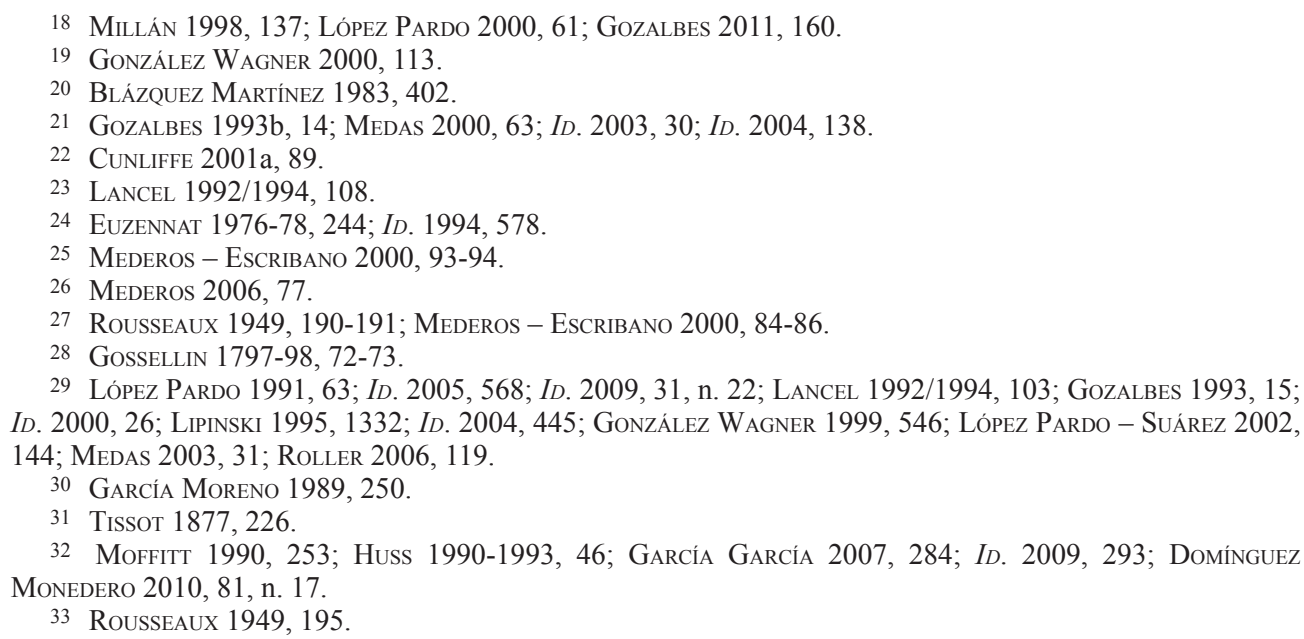


El emplazamiento de Thymiatérion en Tánger está estrechamente relacionado con una ubicación del promontorio de Solóenta (Peripl. 3) en cabo Espartel, "cubierto de árboles", donde se fundaría un santuario a Poseidón, probablemente dedicado a Melqart, ${ }^{34} \mathrm{o}$ a las luchas de Melqart con Anteo, ${ }^{35}$ emplazamiento y dedicatoria a Melqart que compartimos. No obstante, la alternativa principal, que goza de mayor apoyo, es su localización en cabo Cantín, opción que ya fue defendida por Ramusio ${ }^{36}$ y que seguimos encontrando en numerosos investigadores. ${ }^{37}$

La siguiente escala es la mención de una laguna costera con elefantes (Peripl. 4), que podría despertar cierto interés estratégico por un potencial uso de los elefantes norteafricanos en el ejército cartaginés. No obstante, aún no había comenzado su uso militar que sólo es mencionado por las fuentes romanas desde el 262 a.C., en la batalla de Agrigento durante la Primera Guerra Púnica, con elefantes jóvenes y probablemente de sabana, con mayor talla. Aún así, el uso militar ya se conocía desde que Alejandro Magno luchó contra ellos en la batalla del río Hidaspes, afluente del Indo, en el actual Pakistán, el 326 a.C.

Estas marismas con elefantes (Peripl. 4) se han situado en una zona relativamente próxima, aunque con matices entre los autores, bien la Merdja de Muley Bu-Selam o Bu Ez-Zerga en las desembocaduras de los ríos Mharhar, Hachef y Helú, ${ }^{38}$ la Merdja de Sidi Kacem, ${ }^{39}$ la Merdja de Sidi Kacem y del río Tahaddart ${ }^{40}$ o las marismas del río Tahaddart. ${ }^{41}$ En cambio, los partidarios de un trayecto largo se inclinan por las marismas del río Tensift, ${ }^{42}$ que realmente no existen.

El siguiente párrafo es de los más complejos del periplo pues menciona la fundación de cinco ciudades costeras (Peripl. 5), denominadas Karikón Teíchos-Fuerte Cario, Gýtte, Ákra, Mélitta y Árambys, cuya discusión exigiría un artículo específico. Tratando de sintetizar, podríamos decir que un grupo de autores procura situarlas todas en la costa de la península tingitana con el objetivo de lograr un control cartaginés de la península antes de llegar a la ciudad de Lixus. La ubicación que goza de mayor aceptación es la ciudad de Gýtte en Cotta desde Carcopino ${ }^{43}$ hasta fechas recientes. ${ }^{44}$

Por el contrario, otros autores consideran que estas fundaciones se escalonaban a lo largo de la costa marroquí hasta regiones meridionales, siendo un buen ejemplo la propuesta de ubicación de Ákra en Agadir, desde Robiou ${ }^{45}$ hasta autores recientes. ${ }^{46}$

34 LIPINSKI 1995, 1332; ID. 2004, 447.

35 López Pardo 2009, 35.

36 Ramusio 1550, 122.

37 Moffitt 1990, 253; Huss 1990-1993, 47; Schrader 1990, 134; Culican 1991, 543; Keyser 1993, 168; Millán 1998, 157; Díaz del Río 2005, 156, 175; Domínguez Monedero 2009, 273; ID. 2010, 82, n. 30.

38 BlázQuez y Delgado-Aguilera 1921, 413-414, 416, 484; Rebuffat 1973-74, 147; ID. 1985-86, $259,280$.

39 Gozalbes 1993, 16; ID. 1997, 189.

40 LIPINSKI 2004, 447.

41 Euzennat 1976-78, 244; ID. 1994, 564-565; LóPez Pardo 1991, 64; LiPInSKi 1995, 1332.

42 Cary - Warmington 1929, 48; Marcy 1935, 31; Hyde 1947, 142; Moffitt 1990, 253.

43 CARCopino 1943b, 138.

44 López PARdo 1991, 64; ID. 2001, 50, n. 10; LANCEL 1992/1994, 103; GoZALBES 1993, 15; LiPINSKi $1995,1332$.

45 Robiou $1861,199$.

46 Martín de Guzmán 1984, 107; Dilke 1985, 132; Pastor 1987, 153; Moffitt 1990, 253; Díaz del Río $2005,156,175$. 
Si la ubicación de Thymiatérion en Tánger está en función de la aceptación del cabo Solóenta en cabo Espartel, en el caso de las fundaciones costeras la clave es la ubicación del río Líxos, ${ }^{47}$ que los partidarios de la península tingitana identifican lógicamente con el actual río Lucus-Loukos a partir de Quatremère, ${ }^{48}$ con creciente aceptación recientemente. ${ }^{49}$ En este río se observaron cocodrilos durante el s. XVIII, según el viajero inglés Drumond Day. ${ }^{50}$ En cambio, los partidarios de un periplo largo asocian el Líxos con el río Drâa desde Müller ${ }^{51}$ hasta estos los últimos años. ${ }^{52}$ Ciertamente, como señala Rousseaux, ${ }^{53}$ el río Líxos es el primer gran río que encontró la expedición, pero la cuestión es que el periplo no hace referencia a ninguna ciudad preexistente, a pesar de la importancia de Lixus, y parece centrarse en las regiones más meridionales, menos conocidas, de la costa de Marruecos.

La clave del problema está en el párrafo 6, pues no se especifica ni el tiempo durante el cual se realizaron las 5 fundaciones, probablemente refundaciones, ni tampoco el tiempo de desplazamiento desde la última colonia, Árambys, hasta el río Líxos. Es imposible que se realizasen 5 fundaciones simultáneas el mismo día, lo lógico sería al menos un día con mínimo para cada una y el único dato del que disponemos es que una vez superada la laguna con elefantes, las fundaciones comenzaron al día siguiente, o sea, a partir del día 3.5 del viaje. Todo ello hace suponer que las fundaciones comenzaron desde el sur de la Península Tingitana y continuaron en las desembocaduras de los estuarios de los ríos Lucus, Sebú y Sala, actual Bou Regreg, hasta quizás el entorno de la llanura costera de Casablanca y el río Oum er Rbia como límite sur.

Esto implica que la ciudad de Lixus probablemente debió ser una de las primeras refundaciones. En este sentido cabe recordar que se ha situado una de las fundaciones en la actual ciudad de Larache, junto a la desembocadura del río Lucus, o también en Arcila-Asilah, ${ }^{54}$ pero podría ser perfectamente en la propia ciudad de Lixus. La mejor explicación a que Lixus no se nombre es la más simple, era una de la refundaciones citadas por Hannón.

El que se tratase de refundaciones también ayudaría a explicar el gran número de embarcaciones y pobladores de la expedición, aunque las cifras estén sobredimensionadas, pues implicaría que en algunas de estas ciudades podría haber habido resistencia a esta nueva imposición colonial cartaginesa y junto a los pobladores venían embarcaciones militares y tropas que garantizasen el asentamiento de los colonos. En esta línea, creemos que el emplazamiento del río Líxos mencionado en el periplo debió estar situado al sur de estas fundaciones y proponemos que pudo estar en el

47 En el texto griego tanto encontramos el río Líxos y los intérpretes Lixítai, que es la opción que se prefiere por su continuidad desde Ps.-Scílax, Peripl., 112, GonzÁlez Ponce 2010, 773, como el río Lixía y los intérpretes Lixiátai.

48 Quatremère 1857, 259.

49 LipinsKi 1995, 1332; ID. 2004, 455; Gozalbes 1993, 14-15; ID. 1993a, 14; ID. 2000, 27; CuliCAN 1991, 544; López Pardo 1991, 64; Lancel 1992/1994, 103; Domínguez Monedero 2009, 286; ID. 2010, 81, n. 17.

50 Blázquez y Delgado-Aguilera 1921, 415.

51 MÜLler 1855, XXV, 5.

52 Moffitt 1990, 253; Schrader 1990, 126; Huss 1990-1993, 47; Martín de Guzmán 1997, 51; Millán 1998, 128, 158; CunlifFe 2001a, 89; García García 2007, 277, n. 862.

53 Rousseaux 1949, 170.

54 LIPINSKI 2004, 454. 
río Oum er Rbia, que sólo lo ha sugerido Negri, ${ }^{55}$ aunque el río Líxos se ha ubicado también no muy distante, hacia el río Tensift, ${ }^{56} \mathrm{y}$ hasta mediados del s. XIX fue una opción mayoritaria.

La primera razón es la referencia de Ptolomeo del Emporikos kolpos, golfo mercantil entre el río Subur (Sebú) y el río y ciudad de Sala (Bou Regreg y Sala), donde debían encontrarse las principales fundaciones fenicias y púnicas al tratarse el Sebú del principal valle fluvial de Marruecos.

En segundo lugar, la no mención a la ciudad de Lixus, incomprensible, y los datos aportados al describir los habitantes del entorno del río. No tiene sentido que donde existía la gran ciudad de Lixus, con presencia fenicia desde el s. VIII a.C., ${ }^{57}$ sus habitantes sean considerados "nómadas", sólo dedicados al pastoreo de ganado y que exigieron un tiempo para ganarse su confianza e incorporarlos como intérpretes a la expedición (Peripl. 8). Necesariamente tenían que ser pobladores más meridionales que combinaban la pesca con el pastoreo y no Lixitai de la ciudad de Lixus. Los intérpretes, más que pastores, identificación que Desanges ${ }^{58}$ califica de "absurda", debían ser marineros que conocían la lengua púnica por embarcarse en barcos pesqueros gaditanos. Ya uno de los argumentos de Gossellin ${ }^{59}$ para defender la ubicación del río Líxos en el actual Lucus estaba en que difícilmente la población local entendería la lengua púnica en el río Drâa, la opción más defendida por los partidarios de un trayecto largo.

En tercer lugar, explicaría una cadena de fundaciones relativamente escalonadas, incluyendo los tres principales ríos de la costa marroquí, el río Lucus con la ciudad de Lixus, el río Sebú, donde existen fundaciones fenicias en Thamusida y Banasa y el río Bou Regreg, con el importante puerto de Sala. En todo caso, las fundaciones del periplo de Hannón mantienen una localización costera y no penetran al interior frente al caso de Banasa, y cuando se explora al interior del gran río (Peripl. 9-10) ya es sin intención de fundar ningún tipo de factoría.

Esta explicación también ayudaría a comprender el párrafo 7, pues por el río Oum er Rbia se accedía al interior de Marruecos y al pie del Atlas, donde vivían otros dos pueblos, al principio los etíopes, y en el entorno de Atlas los trogloditas, "más rápidos que los caballos en la carrera", que podríamos asociar con los farusios o Pharusii, poblaciones del interior, conductores de carros y caballos. ${ }^{60}$

En todo caso parece utilizarse el nombre de Líxos quizás para más de un río, y si en el actual Lucus su nombre deriva de la ciudad de Lixus, así también podría entenderse la referencia al "río Lixo" y de "esta ciudad [Lixus] (...) que, además estaba

55 Negri 1978.

56 Campomanes 1756, 56 que menciona el Tensif como río Teset; HeEren 1793/1832, 500; KLUGE 1829 , 27-28; Forbiger 1844, 869.

57 Álvarez García - Gómez Bellard 2005, 177.

58 Desanges 1983, 268.

59 Gossellin 1797-98, 77-76.

60 Mel. III, 10, 103; Str. XVII, 3, 7. Para la obra de Mela se han usado las ediciones de Fontes Hispaniae Antiquae (vol. VII, 1-12, 101-112, 1987, editado por V. Bejarano), Les Belles Lettres (1988, editado por A. Silberman) y la Universidad de Murcia (1989, trad. de C. Guzmán Arias); para la de Estrabón, la edición de Loeb Classical Library (nº 267, vol. VIII, libro XVII, 1932/1982, editada por H. L. Jones). 
situada (...) a una distancia casi inmensa de Tánger" ${ }^{61}$ que podría sugerir otro río más meridional con el mismo nombre. Una posible explicación podría derivar de su nombre, si se acepta la sugerencia de Bochart, ${ }^{62}$ a partir del hebreo Laix o Lix, río del león, pues entonces era frecuente en la región el león del Atlas ${ }^{63}$ y su piel era una de las mercancías que cita el Pseudo Escílax. ${ }^{64}$ Es interesante también la mención en Plinio ${ }^{65}$ de un "Hannón, uno de los más ilustres cartagineses, [que] fue el primer hombre que se atrevió a acariciar a un león con su mano y a mostrarlo domesticado".

\section{La isla de Kérne y la fundación de puntos de escala}

El párrafo 8 es importante porque marca una distancia de 3 días entre el río Líxos y la isla de Kérne, la última fundación de la expedición que les sirvió de base de operaciones en dirección al Sur. Entre los partidarios de un trayecto corto, la ubicación preferida oscila entre la desembocadura del río Sebú y el islote de Mogador. La primera propuesta fue situarla en la isla de Samta María des Portugais-Djezira Sidi Youssef, a $23 \mathrm{~km}$ por encima de Mehedia en la desembocadura del río Sebú, ${ }^{66}$ cuya ocupación antigua no fue confirmada en la misión franco-marroquí del Sebú dirigida por Rebuffat. Su argumentación fue retomada por Lipinski, ${ }^{67}$ situándola primero genéricamente en el estuario del río Sebú, y posteriormente más en detalle en la Merja de Beni Ahsen, donde desembocan los ríos Beht y Rom. ${ }^{68}$ Esta solución explicaría la jornada de navegación en dirección al Este dentro de un gran estuario fluvial y ascenso por su cauce. Es una opción que no cabe descartar porque el intenso proceso de sedimentación de la desembocadura del río Sebú no facilita la prospección de su antiguo estuario que precisaría primero de la reconstrucción de su paleocauce.

La opción alternativa es el islote de Mogador, desde su propuesta por Mauny, ${ }^{69}$ que sigue gozando de numerosos partidarios ${ }^{70}$ y que nos parece la más apropiada por los datos arqueológicos actualmente disponibles en Mogador y porque en el río Sebú los emplazamientos se fundan en época fenicia, con un carácter más urbano al ser una región más rica. La descripción del periplo indicaría un recorrido entre el río Líxos/ Oum-er-Rbia de 2 días y un trayecto en dirección Este, una vez sobrepasado el cabo Cantín, de 1 día. Este cabo suponía superar la zona de colonización estable fenicia en la costa marroquí que, de momento, no parece superar los ríos Sebú y Sala. Es importante recordar que cuando se supera el promontorio de Solóenta-cabo Espartel,

61 Plin., $N H, \mathrm{~V}, 1,4$.

62 BoCHart 1646, 711.

63 López Pardo - Mederos 2008, 93, fig. 13-14.

64 Ps.-Scílax, Peripl., 112.

65 Plin., NH, VIII, 21, 55.

66 ReBufFat 1985-86, 261-262; ID. 1988, 199.

67 LIPINSKI 1988, 79; ID. 1995, 1332.

68 LIPINSKI 2004, 459.

69 Mauny 1949, 57.

70 Jodin 1988, 88; EuZennat 1990-92, 223; ID. 1994, 573, 576; Gozalbes 1993, 19; ID. 1993a, 14-15; ID. 2000, 27; Culican 1991, 545; López Pardo 1991, 62; Desanges 2001, 33; Medas 2006, 21, 35; López Pardo - Mederos 2008, 91; GonzÁlez Ponce 2010, 767. 
el periplo señala que navegan hacia el Este (Peripl. 4), aunque la dirección real era hacia el Sureste y otro tanto sucedía al pasar el cabo Cantín (Peripl. 8).

No obstante, un grupo mayoritario de autores, partidarios de un trayecto largo, opta por ubicaciones mucho más meridionales de Kérne, caso de la isla y oasis de Lemsid en la desembocadura del río Saguia el-Hamra, desde Fischer ${ }^{71}$ hasta Peretti, ${ }^{72}$ o el cercano Puerto Pesquero de El Aaiún. ${ }^{73}$

Más al Sur se ha propuesto la isla de Herné de Río de Oro-Villa Cisneros, a partir de Müller ${ }^{74}$ hasta Moffitt, ${ }^{75}$ aunque carece de cualquier evidencia arqueológica según las prospecciones entre 1973-74 de Gran Aymerich ${ }^{76}$ y sus dimensiones son mayores, $5 \mathrm{~km}$ de bojeo y no $1 \mathrm{~km} \cdot{ }^{77}$

Otro numeroso grupo opta por la isla de la bahía de Arguin en Mauritania, desde Ramusio, ${ }^{78}$ defendida también hasta la actualidad, ${ }^{79}$ pero esta isla también carece de cualquier evidencia arqueológica según las prospecciones de Monod ${ }^{80}$ entre 197778. Ya en el s. XVIII, Bougainville ${ }^{81}$ había mencionado la presencia de dos cisternas cubiertas para almacenar agua que atribuye a los cartagineses, pues los portugueses no las citan en sus crónicas.

Finalmente, otra serie significativa de autores se inclina por una isla en el río Senegal a partir de Bonsor, ${ }^{82}$ indicativo de cómo esta expedición se traslada hacia latitudes meridionales. $^{83}$

En todo caso, resulta evidente que la expedición, una vez refundadas las cinco ciudades o asentamientos, ya tiene un carácter más exploratorio, probablemente con un número reducido de embarcaciones, y a partir de entonces sólo instalaron pequeñas factorías, o mejor puntos de escala, pues no se hacen fundaciones en el río Líxos a pesar de que "permanecimos algún tiempo" (Peripl. 6), quizás por ausencia de recursos de interés o insuficiente seguridad, optándose por elegir el emplazamiento insular de Kérne, deshabitado.

\section{El problema del río Chrétes}

Una vez en Kérne, el problema del siguiente párrafo (Peripl. 9) es que no especifica el tiempo del trayecto hasta comenzar a navegar por "un gran río", por el que navegaron a lo largo de un día, con islas en su interior. Esto explica la opción de muchos

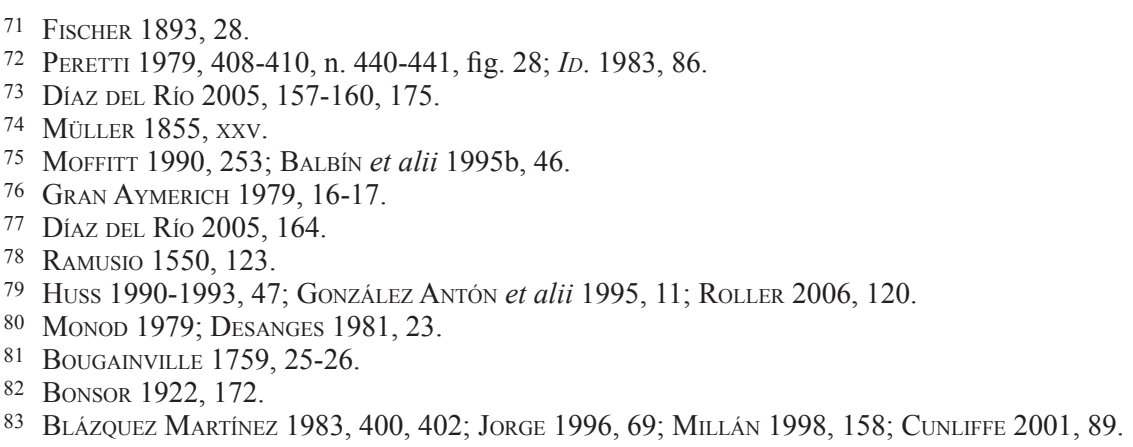


autores por el río Senegal, ${ }^{84}$ pues actualmente es navegable hasta $600 \mathrm{~km}$ hacia el interior en la estación lluviosa. Los partidarios de un trayecto corto sólo tienen la opción del el río Sebú, ${ }^{85}$ ubicando a menudo Kérne en la desembocadura de ambos ríos (vide supra).

El río Sebú, definido en época romana como magnificus et navigabilis, ${ }^{86}$ es sensible a los efectos de la marea hasta $50 \mathrm{~km}$ al interior, y hasta inicios del s. XVI el río era navegable en invierno hasta Fez por pequeñas embarcaciones, ${ }^{87}$ a $232 \mathrm{~km}$ de la desembocadura, siendo probable que Banasa (Sidi Ali bou Djenoun), a $82 \mathrm{~km}$ de la costa, al menos durante el invierno fuese accesible por barco.

Para nosotros, el emplazamiento en Mogador es posible pues sería un lugar conocido y frecuentado ocasionalmente desde época fenicia. Una vez utilizada su bahía como base de operaciones, se desplazarían a explorar las regiones vecinas. La exploración no necesariamente tendría que ser siempre en dirección sur, sino que pudieron ascender de nuevo para penetrar dentro del cauce del río Sebú, que identificamos con el río Chrétes, pues la opción del río Senegal al Sur queda muy distante de Mogador. En el cauce del río fueron atacados por "salvajes vestidos de pieles y armados de piedras", pero es interesante que no mencione que se trataba de poblaciones etíopes negras, lo que podría apuntar a una ubicación más meridional. La mención a "montañas enormes" también sugiere el piedemonte de la región del Atlas. En el entorno de Kérne, según Plinio ${ }^{88}$ más al sur del Chrétes, los pobladores ya eran etíopes.

Es interesante recordar que la mejor etimología hasta ahora propuesta sigue siendo la de Bochart ${ }^{89}$ que traducía el río Chremétes ${ }^{90}$ por nahar cheremat, el río vinoso o del vino, y explicaría también la mención al consumo del vino entre los etíopes de Kérne que menciona el Pseudo-Escílax ${ }^{91}$ o la fundación de Árambys, Har-anbin, monte de viñas o de las uvas, ${ }^{92} \mathrm{o}$ mejor, har 'anbi, ${ }^{93}$ preferible a otras lecturas a partir de $k r t$, cortar, ${ }^{94}$ o del bereber, $K r$-étês, río del lago o río del pantano. ${ }^{95}$ La ubicación de cultivos de viñas mucho más al Sur, en el río Drâa, resulta menos probable.

El segundo río con presencia de cocodrilos e hipopótamos (Peripl. 10) podría tratarse del río Beht, ${ }^{96}$ pues desemboca en el río Sebú y es navegable, desde donde optaron por regresar a Kérne, no indicando nuevamente la distancia entre el río Chrétes o segundo río y el emplazamiento de Kérne. El párrafo 11 menciona "desde allí" una navegación hacia el Sur de 12 días, que podría ser bien desde el río Chrétes-Sebú

\footnotetext{
84 Schrader 1990, 137; Jorge 1992-93, 232; ID. 1996, 69-70; Keyser 1993, 168; Millán 1998, 158; Medas 2000, 68; ID. 2003, 31; Roller 2006, 121; Domínguez Monedero 2010, 84.

85 RebufFat 1985-86, 262; ID. 1988, 199; Lipinski 1988, 79; ID. 1995, 1332; ID. 2004, 459, 462.

86 Plin., $N H, \mathrm{~V}, 1,5$.

87 Pereira 1505-08; Ricard 1927, 238.

88 Plin., NH, VI, 31, 198.

89 Bochart 1646, 713-714.

90 Arist., Metereol., I, 13.

91 Ps.-Scílax, Peripl., 112.

92 Bochart 1646, 712.

93 Bochart 1646, 712; LiPINSKi 2004, 447.

94 López PARdo 2009, 50.

95 Marcy 1935, 70-71.

96 LIPINSKI 1995, 1332; ID. 2004, 460.
} 
hacia el Sur, la opción más razonable, o bien desde Kérne-Mogador hacia el Sur. La cifra coincide sospechosamente con los 12 días de navegación entre las columnas de Heracles y la isla de Kérne en Pseudo-Scílax. ${ }^{97}$ En todo caso, si el punto de salida es el río Chrétes-Sebú, debía atravesar después en dirección hacia el Sur los ríos Sala, Oum er Rbia, Tensif y Ksob hasta alcanzar Mogador, y luego continuar hasta el río Tamri y cabo Aguer-Rhir, resultan posibles los 12 días de navegación en exploración. Allí alcanzarían la región del Alto Atlas ${ }^{98}$ y el cabo Aguer, ${ }^{99}$ con bosques de tuya y arganes productores de un aceite aromático. En cambio, para los partidarios de un trayecto largo ya nos encontraríamos en la región de Cabo Verde del Senegal. ${ }^{100}$

\section{El gran golfo que finaliza en el Cuerno del Oeste}

El trayecto entre el cabo Aguer o Ger, actual cabo Rhir, donde finaliza el Alto Atlas, y la llanura de la desembocadura del río Sus, fue explorado detalladamente durante 2 días (Peripl. 13), con varias desembocaduras de pequeños ríos, hasta divisar núcleos habitados en el puerto de Agadir, ${ }^{101}$ pues observaron "fuegos a intervalos", ${ }^{102}$ traducción más adecuada que "un fuego que subía por todas partes a intervalos". ${ }^{103}$ Los partidarios de un trayecto largo en cambio suelen ubicarlo en la desembocadura del río Gambia. ${ }^{104}$ Una explicación racional propuesta por Villaverde ${ }^{105}$ al vincular los "numerosos fuegos" durante la noche ${ }^{106}$ en la costa del Atlas, con las hogueras que se realizaban durante el solsticio de verano el 21 de junio, es aplicable también al periplo de Hannón, pues es una costumbre que también practicaban las poblaciones indígenas libias de Canarias, marcaba el inicio del año y durante los 9 días siguientes se celebraban las bodas y celebraciones, ${ }^{107}$ coincidiendo además con la temporada de navegación.

Después de aprovisionarse de agua, probablemente en la Founti de Agadir, quizás el mejor punto de aguada de la costa meridional marroquí, navegaron por un gran golfo que los intérpretes denominaban Hespérou Kéras, Cuerno del Oeste o de Occidente, a lo largo de 5 días (Peripl. 14), golfo conocido por los intérpretes que tomaron en el río Lixos, indicativo de que se navegaba con alguna frecuencia hasta estas regiones y que asociamos con el golfo de Agadir. En la desembocadura del río Aoueri, estuario donde hay diversos islotes, vieron una isla enorme, que identificamos con el entorno de la Mar Pequeña y "un lago formado por el mar", actualmente

\footnotetext{
97 Ps.-Scílax, Peripl., 112.

98 LIPINSKI 1995, 1332; ID. 2004, 468.

99 Gossellin 1797-98, 93.

100 Moscati 1972, 122; Decret 1977, 127; Blázquez Martínez 1983, 402; Martín de Guzmán $1984,108$.

101 Gossellin 1797-98, 93; LipINSKi 1988, 79; ID. 1995, 1332; ID. 2004, 468.

102 GonzÁlez Ponce 2009, 136-137.

103 García Moreno - Gómez Espelosín 1996, 118.

104 Martín de GuZmán 1984, 108; Medas 2000, 68.

105 VillaVerde 2001, 53, n. 152.

106 Plin., $N H, \mathrm{~V}, 1,7$.

107 Mederos 2011, 96-103.
} 
la zona inmediata de salinas de Dzér. Es interesante que la vegetación estaba bastante recuperada a mediados del s. XIX, considerándose a la Mar Pequeña "fértil en frutos y arbolado, que proporcionará combustible a las inmediatas islas de Lanzarote y Fuerteventura". ${ }^{108}$

Tanto Garzón, ${ }^{109}$ García Moreno y Gómez Espelosín ${ }^{110}$ o González Ponce ${ }^{111}$ traducen el sustantivo femenino ívँ $\lambda \eta$ como "selva", aunque en la actualidad hay una vegetación notable, pero sólo la propia de un entorno fluvial costero, y no se parece a una selva propiamente hablando. Sin embargo, nos parece más razonable de acuerdo con la edición del texto griego de Simonides ${ }^{112}$ una traducción como "bosque" o "boscoso", que apoya el diccionario de Liddell y Scott. ${ }^{113}$ Desde nuestro punto de vista, la presunción implícita de que Hannón ya se encontraría entonces en un entorno ecuatorial ha llevado a priorizar su traducción como selva frente a bosque.

Por otra parte, la zona estaba poblada (Peripl. 14), pues "por la noche observamos numerosos fuegos encendidos y oímos sonido de flautas, ruido de címbalos y timbales y mucho griterío", por lo que prefirieron abandonar la isla aconsejados por los adivinos que consultaban los oráculos. El sonido producido por los címbalos ha sido atribuido a los atlantes, pobladores de estas regiones según Diodoro. ${ }^{114}$ También recuerda a Mela, quien menciona "los campos de los egipanes y de los sátiros (...) en ellos no hay nada cultivado ni ningún asentamiento o huella de pobladores, sino una prolongada soledad durante el día y un silencio muy vasto, sin embargo, resplandecen de noche numerosos fuegos y se muestran como un campamento extendido espaciosamente, retumban címbalos y tambores y se escuchan flautas que resuenan con más fuerza que tocadas por el hombre". ${ }^{115}$ Incluso se han interpretado los sonidos como propios de un lenguaje silbado, ${ }^{116}$ que aún se conserva actualmente en algún punto del Rif y en la isla de La Gomera, como hemos observado personalmente en ambos lugares.

En todo caso, lo más lógico es que sean sonidos desconocidos que se oían durante la noche cuyo origen no se podía precisar, pues en el Pseudo Aristóteles, cuando se menciona a la isla de Eolo, una de las Lípari, señala que "no es seguro acercarse a aquel lugar de noche (...) pues se escucha con claridad el sonido de tambores y címbalos y una risa con estrépito y el sonido de crótalos". ${ }^{117}$ Es además interesante que en la isla de Eolo, para percibir estos sonidos musicales, no hacía falta ni un entorno selvático, ni siquiera boscoso.

108 Álvarez Rixo 2003, 178-179.

109 GARZÓN 1987, 81-82.

110 García Moreno - Gómez Espelosín 1996, 118.

111 González Ponce 2008, 138-139.

112 SiMONIDES 1864, 30.

113 Liddell - Scott 1940; com. pers. A. M Canto.

114 Diod. III, 57, 1-2, 7 (se han utilizado las ediciones de Gredos [n ${ }^{\circ}$ 294, libros I-III, 2001, trad. de F. Parreu] y de The Loeb Classical Library [vol. II, libros II, 35-IV, 58, 1935, editado por C. H. Oldfather]).

115 Mel. III, 9, 95.

116 SchmitT 1974, 475.

117 Ps. Arist., De Mirab. Ausc., 101 (se ha consultado la edición de Gredos [nº 222, de 1996], trad. de F. J. Gómez Espelosín). 
La existencia de árboles con maderas aromáticas, tanto en el Atlas (Peripl. 12), como en esta isla situada en un estuario (Peripl. 14), la ratifica Plinio ${ }^{118}$ quien menciona a "Los árboles de las islas del entorno de Etiopía y sus bosques fragantes", y en el apartado siguiente menciona los árboles de maderas olorosas del "monte Altas". ${ }^{119}$

En todo caso, la rápida retirada de la isla donde habían desembarcado es indicativa de que la expedición estaba compuesta por muy pocos barcos, quizás sólo $2 \mathrm{o}$ 3 embarcaciones. Si se hubiese tratado de una escuadra, incluyendo un contingente significativo de soldados, su actitud habría sido diferente. Por otra parte, la rápida marcha les impidió realizar aguada y obtener provisiones frescas.

Los autores que defienden un trayecto corto no sugieren el entorno de Mar Pequeña, como hemos planteado, sino que ya desde Agadir se habría navegado hacia las Islas Canarias hasta acabar divisando la gran isla que identifican con Fuerteventura. ${ }^{120}$ En cambio, los partidarios de un trayecto largo optan habitualmente por la isla de Orango o Harang del archipiélago de Bissagos en Guinea Bissau ${ }^{121}$ o las islas de Los, también en Guinea Bissau. ${ }^{122}$

Una vez partieron de la isla, la expedición inicialmente continuó costeando por el golfo presumiblemente en dirección hacia el Hespérou Kéras, pero "debido al calor, resultaba inaccesible", por lo que no desembarcaron (Peripl. 15), optando por separarse de la costa desértica y navegar más en altura. Eso parece inferirse de la traducción, pues durante "cuatro días estuvimos divisando por la noche la costa llena de llamas" (Peripl. 16).

Los 9 días que recoge el periplo de Hannón, 5 navegando hasta la isla en Mar Pequeña en el río Aoueri y 4 más de trayecto hasta el Hespérou Kéras, que no debieron alcanzar pues iban separándose de la costa, coinciden aproximadamente con "el golfo de 616.000 pasos [56 - miles de pasos o milia passuum - x 11 días y noches] cerrado por el promontorio del mons Braca [Atlas], que corre hacia el Ocaso y que se denomina Surrentio", ${ }^{123}$ y con el cálculo que hace de la distancia, "hasta el cabo Héspero hay diez días diez y noches de navegación", ${ }^{124}$ según recoge el periplo de Polibio.

El trayecto a lo largo de una costa inhabitada, desértica, sin puntos de aguada y alimentos, que no habían tampoco podido obtener en la isla donde reembarcaron pronto (Peripl. 14), llevaría a este cambio de ruta. "Hannón, un cartaginés (...) había referido que no le había faltado el mar sino víveres" ${ }^{125}$ pues "A continuación, hay un espacio extenso y sin habitantes". ${ }^{126}$

Un segundo aspecto fundamental, que no se suele tener en cuenta, es la no mención de ningún río importante desde el río Chrétes, donde entraron los barcos de la

118 Plin., NH, XIII, 14, 90.

119 Plin., NH, XIII, 14, 91.

120 Schmitt 1968, 383, 381, lám. 13; Gozalbes 2000, 29; Lipinski 2004, 472.

121 Simões 1946, 165; Casariego 1947, 62; Hyde 1947, 144; Díaz Tejera 1988, 17.

122 Santana et alii $2002,159$.

123 Plin., $N H, \mathrm{~V}, 1,10$.

124 Plin., $N H, \mathrm{~V}, 1,10$.

125 Mel. III, 9, 90.

126 Mel. III, 9, 89. 
exploración. Este aspecto dejaba perplejo a Rennell ${ }^{127}$ al situar el río Chrétes en el río Senegal, pues como partidario de un trayecto largo la expedición habría alcanzado latitudes ecuatoriales, por lo que consideraba que tuvo que haber visto algunos de enorme caudal como el río Grande o el río Sherbro, sugiriendo que por la "extrema brevedad" del relato no son mencionados. Sin embargo, este hecho es una clara prueba de que no se alcanzaron esas latitudes ecuatoriales. La desembocadura de ríos como el Sous pasa casi completamente desapercibida, la del Drâa sólo llama la atención por la altura de ambas márgenes, no por el cauce del agua, y la desembocadura del río Aoueri es casi un espacio lacustre de desembocadura, no un río significativo pues apenas trae agua. Por otra parte, apoya nuestra propuesta que las embarcaciones se fueron alejando de la costa norteafricana, lo que imposibilitó divisar otros ríos más al Sur.

\section{La clave del gran volcán}

Según nuestra interpretación, la navegación del párrafo 16 implica un trayecto de 4 días de navegación desde las proximidades de Mar Pequeña-cabo Juby en dirección noreste hacia las Canarias y genéricamente siguiendo una ruta E-W. Una dirección opuesta, es decir, desde Tenerife hacia cabo Bojador, es lo que sugiere Oliver, ${ }^{128}$ pero irían perdiendo de vista el cabo Juby, y no divisándolo cada vez mejor, lo que sería más lógico de venir de las islas en dirección a la costa africana.

El $1^{\circ}$ día pasaron por el sur de Fuerteventura, divisándola a distancia, el $2^{\circ}$ día estarían hacia el sur de Gran Canaria, el $3^{\circ}$ día remontarían la costa occidental de Gran Canaria hacia el norte de la isla y visualizarían la Punta de Anaga del noreste de Tenerife y el $4^{\circ}$ día rodearían la isla de Tenerife por el Sur en dirección E-W, para remontar luego por el Norte en dirección W-E, o simplemente regresar desde el sur de Tenerife. Según la descripción de Hannón empezaron a divisar a distancia un gran volcán, que sólo podría ser el Teide en Tenerife de $3.700 \mathrm{~m}$, aunque el volcán podía estar en una de las dorsales de Tenerife, pues "había en medio un fuego muy elevado, mayor que los demás, que daba la impresión de alcanzar las estrellas; sin embargo, de día nos dimos cuenta de que dicho fuego era una montaña muy alta, llamada Theôn Óchema" (Peripl. 16), Columna, Pilar o Soporte de los dioses, o quizás Morada de los dioses. ${ }^{129}$ Otra opción es una lectura semítica de Theôn Óchema como rekeb 'elohim, presente en Salmos, ${ }^{130}$ "Los carros de Dios". ${ }^{131}$ Cabe suponer que se van separando de la costa al visualizar a distancia durante la noche el volcán, sin descartar que algunos expedicionarios o los intérpretes lixitas ya debían conocer previamente la existencia de las islas, y aunque tenían la intención de explorarlas, es posible que el volcán les disuadiese de desembarcar en esa isla.

127 RenNell 1830, 439.

128 OLIVER 1863, 50, n. 77.

129 Como nos sugiere A. M Canto.

130 Sal.-Ps. 68, 18.

131 LIPINSKI 2004, 473. 
Los 4 días de navegación de Hannón los recoge en dirección inversa W-E también Plinio, "una elevada montaña que se cierne sobre el mar arde con fuegos eternos; los griegos la llaman Theôn Óchema. A partir de ésta, a cuatro días de navegación, se encuentra un cabo que se llama Hespérou Kéras, en los confines de África, junto a los etíopes hesperios", ${ }^{132}$ que es la ruta sugerida por Oliver. ${ }^{133}$

Según la descripción de Hannón, Theôn Óchema parece situarse en la costa, no en una isla. En cambio, según Mela, podría encontrarse en una isla, pues lo sitúa frente al gran golfo de la costa africana, "Al otro lado de este golfo un monte elevado, Theôn Óchema según lo llaman los griegos, arde con continuas llamas". ${ }^{134}$ En este sentido, es interesante indicar que había una isla llamada Héspera, "cerca del océano que circunda la tierra (...) cerca de Etiopía y del monte a orillas del océano (...) denominado Atlas por los griegos", de carácter volcánico pues "tenía grandes erupciones de fuego". ${ }^{135}$

Como señala Berlioux, ${ }^{136}$ los cartagineses tenían conocimiento directo de los efectos de un volcán pues en Sicilia estaba el monte Etna y las islas Lípari al noreste de Sicilia son de tipo volcánico. Que se trataba de un volcán lo confirma Plinio cuando incluye al Theôn Óchema con otros volcanes como el Etna entre los "lugares [que] están siempre ardiendo", ${ }^{137}$ considerándolo además el más peligroso de todos, "arde con el fuego más violento de todos la cima de Etiopía, denominada Theôn Óchema, y despide llamaradas tórridas con los calores del sol". ${ }^{138}$

También lo confirma el texto del Pseudo Aristóteles, donde señala que "fuera de las columnas de Heracles arden fuegos, unos continuamente, otros sólo de noche, como cuenta el Periplo de Hannón", mencionando a la vez otros volcanes de Lípari, las Pitecusas o el Etna de Sicilia. ${ }^{139}$

La ubicación de este volcán entre los partidarios de un trayecto corto es mayoritariamente en el volcán del Teide en la isla de Tenerife, ${ }^{140}$ por sus dimensiones, visibilidad y vulcanismo reciente, ${ }^{141}$ aunque también se ha ubicado en la Punta del Fraile de Jandía, al sur de la isla de Fuerteventura ${ }^{142}$ y en el continente africano, hacia la región de Ifni, dentro del Anti Atlas, en Djebel Fogo. ${ }^{143}$

Los partidarios de un trayecto largo tienen que desplazarse al menos hasta el Monte Kakulima en Guinea Conakry, denominado antiguamente Monte Sagres, propuesto

132 Plin., NH, VI, 30, 197.

133 OLIVER 1863.

134 Mel. III, 9, 94.

135 Diod. III, 53, 5-6.

136 BerLioux 1884, 71.

137 Plin., NH, II, 106, 236.

138 Plin., NH, II, 106, 238.

139 Ps. Arist., De Mirab. Ausc., 37-38.

140 Humboldt 1816/1995, 208; Oliver 1863, 26, 51, n. 78; JauRegui 1954, 272; SChmitt 1968, 386; ID. 1974, 475; GozalBes 1989, 37; ID. 1993, 13; ID. 1993a, 15; ID. 2000, 30; ID. 2002, 85; ID. 2011, 164, n. 36.

141 CARRACEDo et alii 2006.

142 LIPINSKI 2004, 473.

143 Mauny 1949, 61, n. 1. 
por Rennell, ${ }^{144}$ con algunos continuadores recientes. ${ }^{145}$ No obstante, la opción preferida es el Monte Camerún o Mongo ma Loba, de $4.070 \mathrm{~m}$, la altura principal desde el Alto Atlas, que apenas lo supera con 4.167 y $4.088 \mathrm{~m}$, defendido por Burton, ${ }^{146}$ quien lo prefería por "la proximidad del país de los gorilas", con numerosos seguidores hasta la actualidad, ${ }^{147}$ al que consideran el único volcán activo de la costa africana, pues estuvo brevemente en erupción en 1922, 1954, 1959, 1982, 1999, $2000^{148}$ y febrero de 2012. No se menciona en cambio al Pico do Fogo, en el archipiélago de Cabo Verde, con $2.829 \mathrm{~m}$ y varias erupciones en 1680, 1769, 1785, 1799, 1816, 1847, $1853,1857,1951$ y $1995 .{ }^{149}$

Realmente las únicas opciones de volcanes activos y de gran altura en la costa atlántica norteafricana son sólo dos, el Teide con $3.700 \mathrm{~m}$ y el monte Camerún con $4.100 \mathrm{~m}$, y la elección de uno u otro determina un trayecto corto o largo para el periplo. No hay volcanes en la costa del sur de Marruecos o en el litoral del antiguo Sahara occidental.

\section{La isla de las "gentes salvajes" denominadas gorilas}

Una vez observado de cerca el volcán, la expedición parece iniciar el regreso hacia el punto previo desde donde se separó de la costa. "Después de costear desde allí torrentes de fuego durante dos días, llegamos al tercero a un golfo llamado Nótou Kéras" o Cuerno del Sur (Peripl. 17). Lo lógico es que hiciesen una ruta de regreso ahora en dirección W-E, desde el noreste o sur de Tenerife, pasando el $1^{\circ}$ día por el sur de Gran Canaria, para situarse el $2^{\circ}$ día en el sur de Fuerteventura, alcanzando la gran Punta de Jandía en el extremo sur de la isla, que suponemos mencionada por Hannón como Nótou Kéras, ascendiendo el $3^{\circ}$ día por la costa oriental de Fuerteventura en dirección SW-NE, un trayecto más difícil y lento al tener el viento en contra, pero más factible que por la costa occidental de la isla.

Hay pocas propuestas concretas del emplazamiento del Nótou Kéras en los defensores de un trayecto corto, pudiendo citarse los ríos Sus o Drâa, ${ }^{150}$ el cabo Nun, ${ }^{151}$ el cabo Juby, ${ }^{152}$ el cabo Durnford en Río de Oro, ${ }^{153}$ o la isla de Tenerife. ${ }^{154}$ De los partidarios de un trayecto largo, la que goza de más aceptación es el golfo y bahía

144 RenNell 1830, 428-430.

145 Warmington 1969, 93; Dilke 1985, 48, 132; Амiotti 1987, 44.

146 Burton 1863, 28, 200, 209.

147 Schrader 1990, 130; Jorge 1992-93, 232; ID. 1996, 69; Keyser 1993, 154-155; Medas 2000, 68; ID. 2003, 32; SAntana et alii 2002, 154; SANTANA - Arcos 2002, 47; ID. 2009, 350; Díaz del Río 2005, 162, 177 ; Roller 2006, 122; Domínguez Monedero 2010, 88.

148 Nuome et alii 2009, 538, tabla 1, 540, tabla 3.

149 Amelung - DAY 2002, 47.

150 EuZENNAT 1994, 578.

151 Gossellin 1797-98, 94.

152 LIPINSKI 1988, 79; ID. 2004, 436, 474.

153 OLIVER 1863, 51, n. 78.

154 Sснмітт 1968, 387-388, fig. 5. 
de Sherbro, junto a la isla de Sherbro en Sierra Leona, a partir de Rennell, ${ }^{155}$ que a veces se cita genéricamente como Sierra Leona, ${ }^{156}$ pero también tiene partidarios en la actualidad el golfo de Guinea, ${ }^{157}$ Camerún, ${ }^{158}$ la bahía de Biafra, entre el cabo Formosa y la isla de Fernando Poo, ${ }^{159} \mathrm{o}$ la desembocadura del río Gabón, realmente un estuario de $65 \mathrm{~km}$ donde se recogen las aguas de los ríos Komo y Ebe, que es el mejor puerto del golfo de Guinea, ${ }^{160} \mathrm{o}$ incluso, poco después, el cabo López junto a la desembocadura del río Ogüe u Ogooue, en el Gabón, ${ }^{161}$ denominado cuando fue descubierto en 1473 como cabo Lopes Gonçalvez, que marca el límite entre el Golfo de Guinea y el Atlántico Sur.

Al alcanzar el norte de Fuerteventura, se observaba un gran golfo (Peripl. 18), bahía o lengua de mar, Lsn (h)ym (h)drmy, ${ }^{162} \mathrm{y}$ "en el fondo había una isla semejante a la anterior, ya que contaba con un lago y en dicha isla había otra llena de seres salvajes". También se ha señalado que más que un lago en el interior de una isla se trataría de un lago situado en la marisma que baña el mar, junto al cual había una isla, ${ }^{163}$ lo que permitiría el acceso a las naves.

El golfo debe tratarse del Canal de la Bocaina, que separa las islas de Fuerteventura y Lanzarote, ${ }^{164}$ y la isla con un lago en su interior, podría estar en Lanzarote, dentro del Canal de la Bocaina, quizás en el antiguo puerto y actuales salinas de Janubio ${ }^{165}$, que creemos mejor opción que la sugerida por Lipinski ${ }^{166}$ de la bahía de Corralejo en el noreste de Fuerteventura, a la entrada del Canal de la Bocaina. La opción de una isla grande habitada como Lanzarote explica mejor la presencia de población estable.

Algunos autores ya habían sugerido que este párrafo se desarrolló en una de las Islas Canarias, ${ }^{167}$ en concreto Gran Canaria, ${ }^{168}$ pero nos parece más razonable situarlo en las islas más orientales como Lanzarote. No obstante, los partidarios de un trayecto largo eligen ubicaciones mucho más al Sur, inicialmente en las islas de Cabo Verde, ${ }^{169}$ si bien la opción más aceptada ha sido situarla en la isla de Macauley del golfo de Sherbro de Sierra Leona, ${ }^{170}$ aunque no faltan propuestas para la isla de Fernando Poo o Bioko de Guinea Ecuatorial, ${ }^{171}$ la isla del Príncipe de Guinea Ecua-

155 RENNELL 1830, 434.

156 Martín de GuZmán 1984, 109; Dilke 1985, 132; Аmiotti 1987, 45; Peretti 1979, 53, n. 53; ID. $1983,86$.

157 Bartoloni 1988, 74; Medas 2003, 28; ID. 2004, 141.

158 CunLIFFE 2001, 300; ID. 2001a, 41; PANCHENKO 2009, 192.

159 Huss 1990-1993, 47; Medas 2000, 68; ID. 2003, 32.

160 Ferguson 1969, 7; Schrader 1990, 124.

161 DíAz del Río 2005, 162, 177.

162 LiPINSKi 2004, 469, 474.

163 OLIVER 1863, 48-49, n. 75.

164 LIPINSKI 2004, 474.

165 Escribano - MEderos 1999, 463.

166 LiPINSKI 2004, 474.

167 PÉREZ Del CRISTO 1996, 91.

168 Sсhмitт 1968, 388-389, fig. 5; Gozalbes 2000, 30.

169 Frutuoso 1964, 87; Torriani 1978, 6.

170 Acquaro 1978, 50; Martín de Guzmán 1984, 109.

171 SÉNAC 1966, 530. 
torial ${ }^{172} \mathrm{o}$ en la desembocadura del río Gabón, ${ }^{173}$ sospechosamente el primer lugar donde se identificaron los gorilas. ${ }^{174}$

El emplazamiento de las islas de las Goríllai o Górgades está señalado por Plinio, "el cabo que denominamos Hespérou Kéras (...) enfrente de este cabo, están también las Islas Górgades, morada en otro tiempo de las Gorgonas, y distantes del Continente dos días de navegación, al decir de Jenofonte de Lámpsaco", ${ }^{175}$ lo que hace pensar desde el entorno de cabo Juby se alcanzó primero Fuerteventura el primer día, y fue ascendiendo por la fachada oriental de la costa de Fuerteventura y después de Lanzarote el segundo día.

La opción de situar las islas Górgades en Fuerteventura y Lanzarote y las Islas Hespérides en Tenerife y Gran Canaria, ya fue defendida por Schmitt. ${ }^{176}$ Por nuestra parte, ya hemos planteado que las Islas Canarias recibían tres denominaciones para sus distintas islas: las dos más orientales y áridas como Górgades -Lanzarote y Fuerteventura-; las dos más grandes, centrales, verdes y con mejores acuíferos, como Hespérides o Afortunadas -Gran Canaria y Tenerife-; y las tres más occidentales y pequeñas son citadas sólo como "algunas otras" -Junonia, Pluvialia y Capraria-. ${ }^{177}$

Una segunda cuestión es la de denominar gorilas a los hombres y mujeres "salvajes". Respecto al nombre, ya se ha sugerido que puede proceder de 'oril, no circuncidados, ${ }^{178}$ y sabemos con seguridad que la población aborigen de las Islas Canarias, de origen libio, antes de la conquista no se circuncidaba. En cualquier caso, la supuesta sorpresa por la visión de estas "gentes salvajes" no debía ser mucha pues los marineros del río Líxos que actuaban como "intérpretes [las] llamaban Gorillai" (Peripl., 18), indicando que las conocían previamente.

Desde que Savage ${ }^{179}$ denominó una nueva especie de simios localizada en el río Gabón con el término de Gorilla gorilla, frente al nombre local Enché-eko, porque fue "un término usado por Hannón, al describir los 'hombres salvajes' encontrados en la costa de África, probablemente una de las especies del orangután", se ha utilizado constantemente para reafirmar la visita a las regiones ecuatoriales por los partidarios de un trayecto largo. Así han sido identificados como chimpancés, ${ }^{180}$ pongos -orangutanes- ${ }^{181}$ orangutanes, ${ }^{182}$ gorilas o chimpancés, ${ }^{183} \mathrm{y}$ en particular gorilas ${ }^{184} \mathrm{o}$ más

172 Antichan 1888, 255, 315.

173 Tlatli 1978, 264.

174 Savage $1847,420$.

175 Plin., NH, VI, 31, 199-200.

176 Schmitt 1968, 364, 371; García Moreno 1989, 245.

177 Mederos 2012, 182, 198.

178 LIPINSKI 2004, 474.

179 Savage 1847, 419-420, 422.

180 Johnston 1914-15, 425; Gattefossé 1932, 134.

181 BougainVilLe 1759, 22.

182 Gossellin 1797-98, 99; Hug 1808, 27; Kluge 1829, 28, 46; Kroon 1840, 99; Oliver 1863, 51, n. 78; GARZÓN 1987, 85, n. 20. Se trata además de una especie asiática sólo existente en Indonesia y Malasia.

183 Domínguez Monedero 2010, 90.

184 Lenormant 1869, 203; Antichan 1888, 252; Sagazan 1936, 481; Oikonomides 1977, 36; Santana et alii 2002, 161. 
genéricamente como antropoides o "similares a hombres", ${ }^{185}$ que equivaldría a la superfamilia de los hominoideos, que incluye al hombre y los simios.

Respecto a las famosas pieles de las Górgades, entregadas como ofrenda en un templo de Cartago, no era necesario desollarlas, aunque es la acepción más habitual de dorá, sino que eran parte de la ropa que usaban los habitantes de las Canarias orientales. Así, en Fuerteventura, "los hombres (...) sólo llevan una piel con su pelo, atada sobre la espalda. La mujeres tienen una piel igual, de la misma manera, y dos pieles más, una delante y otra detrás, ceñidas alrededor de la cintura y que les llega hasta la rodilla". ${ }^{186}$ En la descripción del viaje de Hannón que recoge Plinio, a partir de Jenofonte de Lámpsaco, menciona que "el cuerpo de las mujeres estaba cubierto de vello - hirta feminarum corpora- y que los hombres habían escapado a su vista gracias a su velocidad", y al regresar Hannón a salvo del viaje, "ofrendó las pieles de dos mujeres de las Górgades en el templo de Juno, donde quedaron a la vista hasta la toma de Cartago", ${ }^{187}$ o bien de tres mujeres (Peripl. 18). El propio relato no sugiere que se tratase de animales, los hombres, ándras, escaparon por los riscos "y se defendían con las piedras", ${ }^{188}$ mejor traducción que "defendiéndose con lo que tenían a mano", ${ }^{189}$ lo que hace pensar que se trata más de hombres que de gorilas como ya sugería Falconer. ${ }^{190}$ En cambio, las tres mujeres, gunaîkes, "se resistían a seguirles", las capturaron y se defendieron mordiendo y arañando, con lo que decidieron darles muerte, quedándose con sus pieles. No era necesario "desollarlas", como se ha sugerido al creerlas gorilas, sino simplemente quitarles sus vestimentas para hacer una ofrenda demostrativa de haber alcanzado estas latitudes meridionales, por lo que el capitán de la expedición "colgó como curiosidad entre las ofrendas del templo de Juno la piel de las dos, que se conservó hasta la fecha de la destrucción de Cartago". ${ }^{191}$

La distorsión del relato de Hannón se refleja en el texto más tardío de Mela, donde ya no hay hombres y mujeres huyendo, o si se quiere gorilas machos y hembras, sino que en esa "gran isla (...) únicamente moran unas mujeres velludas por todo el cuerpo y, sin unión con varones, espontáneamente fecundas", ${ }^{192}$ resultado de la contaminación del texto de Hannón con el ciclo de Perseo y las Gorgonas. ${ }^{193}$

El énfasis sobre estas "gentes salvajes" no sería tanto por su rareza, el uso de pieles con pelo o la presencia de personas muy velludas, sino porque son las únicas con las que tuvieron contacto directo desde que entraron en contacto con los "nómadas" Lixítai que incorporaron como intérpretes (Peripl. 6-8). No lo hubo en el río Chrétes donde "hombres salvajes vestidos de pieles de animales (...) tirándonos piedras" les impidieron desembarcar (Peripl. 9). Tampoco en la región costera del Alto Atlas, necesariamente próxima a cabo de Aguer donde únicamente son visibles las montañas,

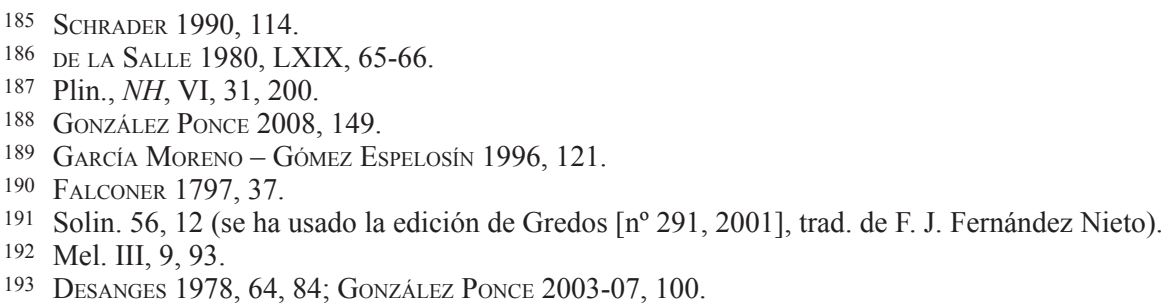


donde los "etíopes (...) huían de nosotros" (Peripl. 11). Ni en la isla en zona lagunar junto a la costa, que sugerimos situar en el estuario de Mar Pequeña, donde sólo "oímos sonido de flautas, ruido de címbalos y timbales y mucho griterío" (Peripl. 14).

Estas características de los hombres y mujeres denominados Gorillai eran propias de algunas poblaciones libias según Diodoro ${ }^{194}$ pues "abrigan sus cuerpos con pieles de cabras", y utilizaban como armas "tres jabalinas y piedras en bolsas de piel (...) procurando superar en agilidad en las persecuciones y (...) en las retiradas. Por lo tanto son hábiles para la carrera y el lanzamiento de piedras", formas de combatir que también practicaban los libios con que se poblaron las Islas Canarias. Así en Gran Canaria, antes de la conquista, se señalaba que "La pelea de estos hombres es con piedras; y no tienen otras armas, excepto un palo corto con el que golpean", ${ }^{195}$ y aún se mantenía durante la conquista, "Usaban ansimesmo de las piedras tiradas a mano (...) Teníenlas escojidas para la pelea mui lisas i amañadas, hacían notable daño con ellas" pues "disparaban (...) cantidad de pedradas, i peñas rodadas. También las mujeres peleaban de lejos con las piedras, i las varas ar[r]ojadas". ${ }^{196}$

\section{Conclusiones}

El Periplo de Hannón se ha interpretado en muchas ocasiones como un relato fantástico, especialmente por quienes defienden su caracterización como una obra literaria falsa, producto de la fabulación, ${ }^{197}$ sin embargo, lo que hemos querido enfatizar, como ya ha señalado Domínguez Monedero, ${ }^{198}$ es que "no hay nada de sobrenatural ni mítico". También se ha pretendido avanzar en su interpretación a pesar de que ya algunos autores consideran que "A estas alturas, las posibilidades de análisis que brinda un texto tan breve y tan poco pretencioso están prácticamente agotadas". ${ }^{199}$

En nuestra interpretación de un trayecto corto del periplo hemos planteado como novedades la asociación de una de las fundaciones de periplo con la propia ciudad de Lixus que por eso no es nombrada (Peripl. 5). Un trayecto no lineal del periplo, y después de la fundación de Kérne (Peripl. 8) en Mogador, la expedición retrocede y explora el río Chrétes (Peripl. 9) que asociamos con el río Sebú. Los fuegos en el horizonte que vinculamos con celebraciones del solsticio de verano y las festividades que continuaban varios días después, propias de los libios (Peripl. 13). Una escala en la desembocadura fluvial y laguna de Mar Pequeña (Peripl. 14), la primera vez que se plantea. La posible asociación del Nótou Kéras con la Punta de Jandía en el sur de Fuerteventura (Peripl. 17). Y finalmente, que los hombres, ándras y las tres mujeres, gunaîkes, "salvajes" llevaban una piel con su pelo, atada sobre la espalda, como

194 Diod. III, 49, 3-5.

195 ZURARA 1998, 53.

196 SEDEÑo 1978, 367, 375.

197 García Moreno - Gómez Espelosín 1996, 101-102.

198 Domínguez Monedero 2010, 92.

199 González Ponce 2010, 769. 
era habitual entre la vestimenta de los indígenas libios de Lanzarote y Fuerteventura (Peripl. 18).

El territorio que debía controlar Juba II, más o menos directamente, a finales del s. I a.C. era la Mauretania útil, que se cifraba en 467.000 pasos, ${ }^{200}$ es decir, 8.3 días de navegación a 56 mil pasos -o milia passuum-diarios. ${ }^{201} \mathrm{Si}$ observamos el periplo de Hannón, a partir del día 3.5, se suceden 5 refundaciones de ciudades que creemos ubicables en los ríos Lucus, Sebou, Sala y quizás alguno en la llanura costera de la región de Casablanca o en el río Oum er Rbia. Si sumamos un día por refundación implica que el viaje ya habría recorrido 8.5 días de trayecto, faltando el tiempo que necesitó entre la última refundación y alcanzar el río Líxos. Es decir, las refundaciones debieron serlo sólo en la Mauretania útil. Otro dato en este sentido sobre el Marruecos conocido es la distancia de 7 días y 7 noches desde Solóenta-cabo Espartel hasta la isla Kérne que sugiere el periplo de Pseudo-Escílax. ${ }^{202}$

Más al Sur, el periplo cartaginés de Hannón recorrió una ruta que ya debía ser conocida no sólo por los marinos del río Líxos que actuaban como intérpretes, como demuestra perfectamente el propio periplo, sino que se trataban de unos parajes que ya habían sido explorados por los fenicios como está bien demostrado en el islote de Mogador. ${ }^{203}$ En las sucesivas escalas que hacen con los intérpretes, primero el islote de Kérne (Peripl. 8), río Chrétes (Peripl. 9), los etíopes del Alto Atlas costero, en el entorno de Cabo Aguer, cuya lengua desconocían (Peripl. 11), el gran golfo "que, a decir de los intérpretes, se llamaba Herpérou Kéras" (Peripl. 14), el volcán o Theôn Óchema (Peripl. 16), "un golfo llamado [por los intérpretes] Nótou Kéras" (Peripl. 17) y con los hombres y mujeres "de cuerpo muy peludo, a las que los intérpretes llamaban Gorillai" (Peripl. 18), no parece que hubiesen muchas sorpresas como ya ha enfatizado García Moreno. ${ }^{204}$ Probablemente la mayor sorpresa fuese encontrar el volcán activo, emitiendo lava, que pudo ser la razón última para redactar este periplo, por lo que como señala Domínguez Monedero "poco de descubrimiento hay en su empresa". ${ }^{205}$

Desde la fundación del último punto de escala o factoría en el islote de Kérne, en la expedición de Hannón primó una primera inspección de evaluación antes que cualquier tipo de exploración detallada en tierra, indicativo de que se trataba de apenas 2 o 3 barcos, con una tripulación limitada, pues sólo se detienen a realizar aguada en Agadir, desembarcan brevemente en una de las islas de Mar Pequeña embarcando al oír sonidos de música y gritos humanos, y sólo vuelven a hacerlo cuando desembarcan al final del texto en la isla donde había hombres y mujeres salvajes.

La falta de agua y provisiones para finalizar la expedición exploratoria sólo es comprensible en un trayecto corto que alcanzara el inicio del desierto del Sahara, pues si se defiende un trayecto largo, como hace por ejemplo Díaz del Río, ${ }^{206}$ sólo

200 Plin., NH, V, 2, 21.

201 Mederos 2013, 251-253.

202 Ps.-Scílax, Peripl., 111.

203 López Pardo - Mederos 2008.

204 García Moreno 1989, 249-250.

205 Domínguez Monedero 2009, 289.

206 Díaz del Río 2005, 162. 
puede señalar que resulta "insólito" e "imposible" que en esas latitudes ecuatoriales, abundantes en agua, fruta y caza, no hayan podido continuar por falta de mantenimientos.

Otro tanto sucede con la ausencia de ríos importantes al sur del río Chrétes, lo que dejaba perplejo a Rennell ${ }^{207}$ que lo localizaba en el río Senegal, pues siendo partidario de un trayecto largo hasta latitudes ecuatoriales, consideraba que tuvo que haber visto algunos de enorme caudal como el río Grande o el río Sherbro, siendo en cambio una clara prueba de que no se alcanzaron esas latitudes ecuatoriales y que las embarcaciones se fueron alejando de la costa norteafricana, lo que imposibilitó divisar otros ríos más al Sur.

Por Arriano conocemos que el viaje de Hannón duró 35 días, hasta que cambió de rumbo, ${ }^{208}$ y no tuvo tiempo de alcanzar las latitudes ecuatoriales que a veces se suponen. Es importante que Plinio señale que navegó "hasta los confines de Arabia", ${ }^{209} \mathrm{o}$ lo que se entendía como el límite del mundo conocido y el desierto meridional.

El recorrido realizado por Hannón desde que partió del río Chrétes, o si no, desde Kérne, hasta el final de la expedición son 26 días y se adecúa bien a los datos que conocemos de época romana. De acuerdo con nuestra reconstrucción serían 12 días del Chrétes-Sebú hasta el Alto Atlas-cabo Aguer, 2 días hasta Agadir-río Sus, 5 días hasta Mar Pequeña, 4 días avanzando hacia el Herpérou Kéras-cabo Juby y desvío para explorar el volcán del Teide en Tenerife, 3 días regresando de Tenerife por Gran Canaria y Fuerteventura, hasta alcanzar el sur de Lanzarote donde se situaría el episodio con las "gentes salvajes", iniciando desde el sur de Lanzarote el retorno en dirección hacia cabo Aguer y Agadir. Estos 26 días, sumados a los 8.5 días anteriores, totalizan 34.5 días, que difícilmente pueden ser una coincidencia con los 35 días que menciona Arriano que duró el trayecto hacia el Sur de la expedición de Hannón.

\section{Bibliografía}

Alvar Ezquerra, J. (1999): “Los fenicios en Occidente”, [en] J. Ma Blázquez - J. Alvar - C. G. Wagner, Fenicios y cartagineses en el Mediterráneo, Madrid, 311-447.

Álvarez García, N. - Gómez Bellard, C. (2005): “La ocupación fenicia. II. Las cerámicas”, [en] C. Aranegui (ed.), Lixus 2. Ladera Sur. Excavaciones arqueológicas marroco-españolas en la colina fenicia (=Saguntum Extra 6), Valencia, 161-178.

Álvarez Rixo, J. A. (2003 [1866]): Historia del Puerto del Arrecife. En la isla de Lanzarote, una de las Canarias, Tenerife (edición de M. Torres Stinga).

Amelung, F. - DAY, S. (2002): "InSAR observations of the 1995 Fogo, Cape Verde, eruption: Implications for the effects of collapse events upon islands volcanoes", Geophysical Research Letters 29/12, 471-4.

Аміотті, G. (1987): “Cerne: “ultima terra”, [en] M. Sordi (ed.), Il confine nel mondo classico (=Contributi dell’Istituto di Storia Antica 13), Milano, 43-49.

207 RenNeLl 1830, 439.

208 Arrian., Ind., VIII, 43, 11.

209 Plin., $N H$, II, 67, 169. 
Antichan, P. H. (1888): Grands voyages de découvertes des anciens, Paris.

Atoche, P. - RAmírez, Ma A. (2011): "Nuevas dataciones radiocarbónicas para la Protohistoria canaria: el yacimiento de Buenavista (Lanzarote)", Anuario de Estudios Atlánticos 57, 139-170.

Balbín, R. de - Bueno, P. - González Antón, R. - Arco, Ma C. del (1995): “The Zinete Stone", Sahara 7, 39-50.

Bartoloni, P. (1988): "Le navi e la navigazione”, [en] S. Moscati (ed.), I Fenici, Milano, 72-77.

Berlioux, E. F. (1884): La terre habitable vers l'Équateur par Polybe. Notice sur cet ouvrage et Sur les itinéraires des Anciens dans l'Afrique occidentale, Paris.

Blázquez y Delgado-Aguilera, A. (1921): "Las costas de Marruecos en la Antigüedad", BRAH 79, 400-418 y 481-509.

Blázquez Martínez, J. Ma (1983): “La expansión cartaginesa", [en] Historia de España Antigua. I. Protohistoria, Madrid, 393-413.

Blompvist, J. (1979-80): The Date and Origin of the Greek Version of Hanno's Periplus. With an edition of the text and a translation (=Scripta Minora 3), Lund.

Bochart, S. (1646): “Cap. XXXVII. Phenices in Africae parte Occidentali ad Oceanum”, [en] Geographiae sacrae pars prior, Phaleg, seu de dispersione gentium et terrarum divisione facta in aedificatione turris Babel pars altera, Chanaan, seu de coloniis et sermone Phoenicum, Caen, 710-715.

Bonsor Saint Martin, G. (1922): "El Coto de Doña Ana (una visita arqueológica)", BRAH 81/2-4, 152-174.

Bougainville, J. P. DE (1759): "Mémoire sur les découvertes et les établissements faits le long des côtes d'Afrique par Hannon, amiral de Carthage", Mémoires de l'Académie des Inscriptions et Belles-Lettres 26, 10-45 y 260-317.

Burton, R. (1863): Abeokuta and the Camaroons Mountains. An Exploration, vol. II, London.

Campomanes, P. Rodríguez, Conde de (1756): Antigüedad marítima de la República de Cartago, con el periplo de su general Hannón, Madrid.

Candau, J. M. - González Ponce, F. J. - Chávez, A. L. (eds.), (2009): Libyae Lustrare Extrema. Realidad y literatura en la visión grecorromana de África. Estudios en honor del Profesor Jehan Desanges, Sevilla.

Carcopino, J. (1943): Le Maroc Antique (=La suite des temps 10), Paris.

Carracedo, J. C. - Rodríguez Badiola, E. - Guillou, H. - Scaillet, S. - Paterne, M. - Pérez Torrado, F. J. - Paris, R. - Fra-Paleo, U. - Hansen, A. (2006): "Geocronología e historia volcánica del complejo volcánico del Teide y de las dorsales de Tenerife”, [en] J. C. Carracedo (ed.), Los volcanes del Parque Nacional del Teide. El Teide, Pico Viejo y las dorsales activas de Tenerife, Madrid, 69-97.

CARY, M. - Warmington, E. H. (1929): The Ancient Explorers, London.

Casariego Fernández-Noriega, J. E. (1947): El Periplo de Hannon de Cartago, Madrid.

Culican, W. (1991): "Phoenicia and Phoenician Colonization", [en] J. Boardman - I. E. S. Edwards - N. G. L. Hammond - E. Sollberger - C. B. F. Walker (eds.), The Cambridge Ancient History. III (2), The Assyrian and Babylonian Empires and other States of the Near East. From the Eighth to the Sixth Centuries B.C., Cambridge, 461-546 (2a ed.). 
Cunliffe, B.

(2001): Facing the Ocean. The Atlantic and its Peoples 8000 BC-AD 1500, Oxford. (2001a): The extraordinary voyage of Pytheas the Greek, London.

Decret, F. (1977): Carthage ou l'empire de la mer, Paris.

DesAnges, J.

(1978): Recherches sur l'activité des Méditerranéens aux confins de l'Afrique (VI siècle avant J.C.-IVE siècle après J.C.), (=Collection de l'École Française de Rome 38), Roma. (1981): “Le point sur le 'périple d'Hannon': controverses et publications récentes", Enquêtes et Documents. Nantes-Afrique-Amérique 6, 11-29.

(1983): "Des interprètes chez les "Gorilles": réflexions sur un artifice dans le "Periple de Hannon", [en] I Congresso Internazionale di Studi Fenici e Punici (Roma 1979), (=Collezioni di Studi Fenici 16/1), Roma, 267-270.

(2001): "Les îles Fortunées et leur environnement africain d'après Pomponius Méla et Pline l'Ancien", [en] C. Hamdoune (ed.), Vbiqve amici. Mélanges offerts à Jean-Marie Lassère, Montpellier, 19-34.

(2006): "La toponymie du périple d'Hannon dans la Géographie de Ptolémée", Pallas 72, 21-34.

Díaz del Río Recacho, J. (2005): "El Periplo de Hannón”, [en] V. Peña - C. González Wagner - A. Mederos (eds.), La navegación fenicia: tecnología naval y derroteros (Madrid 2002), Madrid, 155-178.

Díaz Tejera, A. (1988): “Las Canarias en la antigüedad”, [en] F. Morales Padrón (ed.), Gran Enciclopedia de España y América. Canarias y América, Madrid, 13-32.

Dilke, O. A. W. (1985): Greek and Roman Maps, Ithaca, New York.

Domínguez Monedero, A. J.

(1987): "Los libiofenicios y la interpretación del significado de su presencia en el sur peninsular", [en] M. Olmedo (ed.), I Congreso Hispano Africano de las Culturas Mediterráneas (Melilla 1984), Granada, vol. I, 129-138.

(2009): "Lixus y los lixitas en el Periplo de Hanón”, [en] Candau - González Ponce Chávez (eds.), 2009, 271-290.

(2010): "El viaje de Hanón de Cartago y los mecanismos de exploración fenicios", [en] F. Marco Simón - F. Pina - J. Remesal (eds.), Viajeros, peregrinos y aventureros en el Mundo Antiguo (=Col.lecció Instrumenta 36), Barcelona, 77-93.

Escribano, G. - Mederos, A. (1999): "Evolución histórica de puertos y ensenadas de Lanzarote y Fuerteventura", [en] E. R. de León - A. F. Martín Hormiga - M ${ }^{\mathrm{a}}$ J. Alonso (eds.), VIII Jornadas de Estudios sobre Lanzarote y Fuerteventura (Arrecife 1997), Madrid-Arrecife, vol. I, 455-481.

EUZENNAT, M.

(1976-78): "Pour une lecture marocaine du Periple d'Hannon", Bulletin du Comité des Travaux Historiques, N.S. Afrique du Nord 12-14, 243-246.

(1990-92): "Retour à Cernè”, Bulletin du Comité des Travaux Historiques, N.S., Afrique du Nord 23B, 222-223.

(1994): “Le Périple d'Hannon", Comptes Rendus de l'Académie des Inscriptions et BellesLettres 1994, 559-580.

FALCONER, T. (1797): The voyage of Hanno, translated and accompanied with the Greek text; explained from the accounts of modern travellers; defended against the objections of Mr. Dodwell and other writers, London. 
Ferguson, J. (1969): “Classical Contacts with West Africa”, [en] L. Thompson - J. Ferguson (eds.), Africa in Classical Antiquity, Ibadan, 1-25.

FISCHER, C. Тн. (1893): De Hannonis Carthaginiensis periplo, Leipzig.

Forbiger, A. (1844): Handbuch der alten Geographie aus den Quellen bearbeitet. II. Politische Geographie der Alten. Asia. Africa, Leipzig.

Frutuoso, G. (1964 [1584-90]): Saudades da Terra, [en] E. Serra Rafols - J. Régulo - S. Pestana (eds.), Las Islas Canarias de "Saudades da Terra" (=Fontes Rerum Canariarum XII), La Laguna.

GARCÍA GARCíA, A. M ${ }^{\mathrm{a}}$

(2007): Juba II, rey de Mauritania: traducción y comentario de sus fragmentos, Tesis Doctoral, Universidad de La Laguna.

(2009): Juba II y las Islas Canarias, Sevilla-Tenerife.

García Moreno, L. A. (1989): "Precedentes grecorromanos de la navegación atlántica de Bartolomeu Dias: en torno al Periplo de Hanón", [en] Bartolomeu Dias e a sua época, Porto, vol. II, 237-257.

García Moreno, L. A. - Gómez Espelosín, F. J. (1996): Relatos de viajes en la literatura griega antigua, Madrid.

Garzón Díaz, J. (1987): “Hannon de Cartago, Periplo (Cod. Palat. 398 fol. 55r-56r)”, Memorias de Historia Antigua 8, 81-85.

Gattefosse, J. (1932): “L'Atlantide et le Tritonis occidental. Le rôle des peuples du Sahara occidental dans le développement de la Civilisation", Bulletin de la Société de Préhistoire du Maroc 6/2, 51-152.

GonzÁlez Antón, R. - Balbín, R. De - Bueno, P. - Arco, Ma C. Del (1995): La piedra zanata, La Laguna.

GonzÁlez Ponce, F. J.

(2003-07): "Xénophon de Lampsaque et le Périple de Hannon de Heidelberg", Orbis Terrarum 9, 95-118.

(2008): Periplógrafos griegos I. Épocas Arcaica y Clásica I: Periplo de Hanón y autores de los siglos VI y V a.C. (=Monografías de Filología Griega 19), Zaragoza.

(2010): "Veracidad documental y deuda literaria en el Periplo de Hanón, 1-8", [en] E. Ferrer (ed.), VI Coloquio Internacional del Centro de Estudios Fenicios y Púnicos: Los púnicos de Iberia. Proyectos, revisiones, síntesis (Sevilla 2009), (=Mainake 32/2), Sevilla, 761-780.

(2011): "Hanno von Karthago (2208)", [en] H. J. Gehrke (ed.), Die Fragmente der Griechischen Historiker, V, Die Geographen, Leiden (Brill Online: http://referenceworks. brillonline.com/entries/fragmente-der-griechischen-historiker-v/hanno-von-karthago2208-a2208).

GonzÁlez Wagner, C.

(1999): "Fenicios y púnicos en el norte de África y en el Mediterráneo occidental", [en] J. Ma Blázquez - J. Alvar - C. G. Wagner, Fenicios y cartagineses en el Mediterráneo, Madrid, 449-654.

(2000): Cartago, una ciudad, dos leyendas, Madrid.

Gossellin, P. F. J. (1797-98): Recherches sur la géographie systématique et positive des anciens; pour servir de base à l'histoire de la géographie ancienne, I, Paris. 
Gozalbes Cravioto, E.

(1989): "Sobre la ubicación de las islas de los Afortunados en la antigüedad", Anuario de Estudios Atlánticos 35, 17-43.

(1993): “Algunas observaciones acerca del Periplo de Hannon”, Hispania Antiqua 17, 7-19.

(1993a): "Comercio y exploración del Sahara en la Antigüedad Clásica", Estudios Africanos 7/12-13, 9-33.

(1997): Economía de la Mauritania Tingitana (Siglos I a. de C.-II d. de C.), Ceuta.

(2000): “Más allá de Cerné", Eres (Arqueología) 9/1, 9-42.

(2002): “Los pueblos del África Atlántica en la Antigüedad”, Eres (Arqueología) 10, 6196.

(2011): “África en el imaginario: las exploraciones geográficas del rey Juba II de Mauretania", Studia Historica, Historia Antigua 29, 153-181.

Gran Aymerich, J. M. J. (1979): "Prospections archéologiques au Sahara atlantique (Río de Oro et Seguiet el Hamra)", Antiquités africaines 13, 7-21.

HeEren, A. H. L.

(1793): Ideen über die Politik, den Verkehr und den Handel der vornehmsten Völker der alten Welt. 2 (1). Afrikanische Völker. Carthager. Aethioper. Aegypter, Gottingen.

(1832): Historical Researches into the Politics, Intercourse, and Trade of the Carthaginians, Ethiopians, and Egyptians, vol. I, Oxford.

Hug, J. L. (1808): Hannonis periplus, Friburgi/Freiburg.

Humboldt, A. DE

(1816): Voyages aux régions équinoxiales du Nouveau Continent, fait en 1799, 1800, 1801, 1802, 1803 et 1804, Paris.

(1995): Viaje a las Islas Canarias, Tenerife (edición de M. Hernández González).

Huss, W.

(1990): Die Karthager, München.

(1993): Los Cartagineses, Madrid.

Hyde, W. W. (1947): Ancient Greek Mariners, New York.

JaÚREGUI y Gil-Delgado, J. J. DE (1954): “Las Islas Canarias y la carrera del oro y la púrpura en el periplo de Hannon", [en] I Congreso Arqueológico del Marruecos Español (Tetuán 1953), Tetuán, 271-276.

Jodin, A. (1988): “Les Phéniciens à Mogador”, [en] Les Phéniciens a la conquête de la Méditerranée, Les Dossiers de Histoire et l'Archéologie 132, 88-91.

Johnston, H. H. (1914-15): "Notes on Ptolemy's West Africa", Journal of the African Society $14,423-426$.

Jorge Godoy, S.

(1992-93): "Los cartagineses y la problemática del poblamiento de Canarias", Tabona 8/1, 229-236.

(1996): Las navegaciones por la costa atlántica africana y las Islas Canarias en la antigüedad (=Estudios Prehispánicos 4), Tenerife.

Keyser, P. T. (1993): "From Myth to Map. The Blessed Isles in the First Century B.C.", The Ancient World 24/2, 149-168.

Kroon, J. H. (1840): Dissertatio geographico-literaria inauguralis, qua continetur annotatio in Hannonis periplum, Zutphaniae/Zutfen. 
LANCEL, S.

(1992): Carthage, Paris.

(1994): Cartago, Barcelona.

Lenormant, F. (1869): Manuel d'Histoire Ancienne de l'Orient jusqu'aux Guerres médiques. III. Phéniciens-Arabes-Indiens, Paris.

Liddell, H. G. - Scott, R. (1940): A Greek-English Lexicon, New York (7ª ed.).

LIPINSKI, E.

(1988): “Carthage et Tarshish", Bibliotheca Orientalis 45/1-2, 60-81.

(1995): “The Phoenicians", [en] J. M. Sasson (ed.), Civilizations of the Ancient Near East. II, New York, 1321-1333.

(2004): Itineraria Phoenicia (=Studia Phoenicia 18; Orientalia Lovaniensia Analecta 127), Leuven/Louvain.

LóPEZ PARdo, F.

(1991): "El Periplo de Hannon y la expansión cartaginesa en el África Occidental”, [en] B. Costa - J. H. Fernández Gómez (eds.), La Caída de Tiro y el auge de Cartago. V Jornadas de Arqueología Fenicio-Púnica (Ibiza 1990), (=Trabajos del Museo Arqueológico de Ibiza 25), Ibiza, 59-71.

(2000): El empeño de Heracles. La exploración del Atlántico en la Antigüedad, Madrid. (2001): "Sandáraca, el ámbar de los dioses, en las costas de la factoría fenicia de Mogador/ Kerné (Marruecos Atlántico)", Akros 1, 48-53.

(2005): “Tingentera, Tingi y el mito de Anteo", Mayurqa 30/2, 567-575.

(2009): "Marinos y colonos fenicios codificando la costa atlántica africana", [en] Candau - González Ponce - Chávez (eds.), 2009, 25-51.

López Pardo, F. - SuÁrez Padilla, J. (2002): "Traslados de población entre el norte de África y el sur de la Península Ibérica en los contextos coloniales fenicio y púnico”, Gerión 20/1, 113-152.

López Pardo, F. - Mederos, A. (2008): La factoría fenicia de la isla de Mogador y los pueblos del Atlas (=Canarias Arqueológica Monografías 3), Sevilla-Tenerife.

Marcy, G. (1935): “Notes linguistiques autour du périple d'Hannon”, Hespéris 21/1-2, 21-72.

Martín de GuZMÁn, C.

(1984): Las culturas prehistóricas de Gran Canaria, Madrid-Las Palmas.

(1997): "De arqueología canaria: planteamientos teóricos e historiográficos", [en] A. Millares - P. Atoche - M. Lobo (eds.), Homenaje a Celso Martín de Guzmán (1946-1994), Madrid-Las Palmas, 29-64.

Mauny, R. (1949): “Autour d'un texte bien controversé: le 'périple’ de Polybe (146 av. J.C.)”, Hespéris 36/1, 47-67.

MEDAS, S.

(2000): La marineria cartaginese: le navi, gli uomini, la navigazione (=Sardegna Archeologica, Scavi e Ricerche 2), Sassari.

(2003): "La navigazione fenicio-punica nell'Atlantico: considerazioni sui viaggi di esplorazione e sul Periplo di Annone", Byrsa 1, 13-48.

(2004): De Rebus Nauticis. L'arte della navigazione nel mondo antico, Roma.

(2006): “...Essendo finiti i viveri, non navigammo oltre”. Introduzione allo sudio del Periplo di Annone (=Temi di Archeologia Punica 2), Lugano. 
Mederos Martín, A.

(2006): "El periplo norteafricano de Ofelas", Gerión 24/1, 65-84.

(2011): "Sacrificios de niños y sustitutorios de ovicápridos al dios sol šmš en el litoral atlántico norteafricano", Byrsa 19-20, 79-127.

(2012): "Las columnas de Atlas. El periplo africano de Statius Sebosus de Gades a las Islas Afortunadas", [en] F. Prados - I. García - G. Bernard (eds.), Confines (Alicante 2010), Alicante, 175-209.

(2013): "Los periplos atlánticos norteafricanos de Polibio y Juba II trasmitidos por Plinio (N.H., V, 9-10)”, Gerión 31, 239-268 (http://dx.doi.org/10.5209/rev_GERI.2013. v31.43621).

Mederos, A. - Escribano, G. (2000): “El periplo norteafricano de Hannón y la rivalidad gaditano-cartaginesa de los siglos IV-III AC", Gerión 18, 77-107.

Millán León, J. (1998): Gades y las navegaciones oceánicas en la Antigüedad (1000 a.C.500 d.C.), Écija-Sevilla.

Moffitt, J. F. (1990): “Philostratus and the Canaries”, Gerión 8, 241-261.

Monod, T. (1979): “A propos de l'île Herné (baie de Dakhla, Sahara occidental)”, Bulletin d' Institut Fondamental du Afrique Noire, sér. B, 41/1, 1-34.

Moscati, S. (1972): I Fenici e Cartagine, Torino.

MüLLER, K. (1855): Geographi Graeci minores. E codicibus recognovit, prolegomenis, annotatione, indicibus instruxit, tabulis aeri incisis illustravit Carolus Mullerus, vol. I, Paris.

Negri, C. DE (1978): “Considerazioni nautiche sul 'Periplo' di Annone”, Miscellanea di Storia delle Esplorazioni 3, 33-65.

Oikonomides, A. N. (1977): Hanno the Carthaginian. Periplus or Circumnavigation (of Africa), Chicago.

Oliver y Hurtado, J. (1863): Periplos ibéricos. Discursos leídos ante la Real Academia de la Historia en la recepción pública de Don José Oliver y Hurtado, presbitero, Madrid.

Panchenko, D. (2009): "Parmenides, the Nile and the Circumnavigation of Africa by the Phoenicians”, [en] Candau - González Ponce - Chávez (eds.), 2009, 189-193.

Pastor Muñoz, M. (1987): "El Norte de Marruecos a través de las fuentes literarias griegas y latinas. Algunos problemas al respecto", [en] M. Olmedo (ed.), I Congreso Hispano Africano de las Culturas Mediterráneas (Melilla 1984), Granada, vol. I, 149-171.

Pereira, D. P. (1927 [1505-08]): Esmeraldo De Situ Orbis, [en] R. Ricard (ed.), "La cote atlantique du Maroc au début du XVI ${ }^{\mathrm{e}}$ siècle d'après des instructions nautiques portugaises", Hesperis 7, 229-258.

Peretti, A.

(1979): Il periplo di Scilace. Studio sul primo portolano del Mediterraneo (=Biblioteca di Studi Antichi 23), Pisa.

(1983): "I peripli arcaici e Scilace di Carianda", [en] F. Prontera (ed.), Geografia e geografi nel mondo antico. Guida storica e critica, Bari, 69-114.

PÉReZ Del CRISto, C. (1996 [1679]): Excelencias y antigüedades de las siete Islas de Canaria. Primera Parte. En que se comprenden las Excelencias de estas Islas en los renombres que les dió la Antigüedad, Tenerife (facsímil). 
Quatremère, E. M. (1857): “Die Phoenizier (les Phéniciens) von Dr. Movers, T. I, 1841; t. II, $1^{\text {ère }}$ partie, $1849,2^{\mathrm{e}}$ partie, 1850; t. III, $1^{\text {ère }}$ partie, 1856", Journal des Savants 1857,249 267.

Ramusio, G. B. (1550): Primo volume delle navigationi et viaggi nel qual si contiene la descrittione dell'Africa nel qual si contiene la descrittione dell'Africa, et del paese del Prete Ianni, con varii viaggi, dal mar Rosso a Calicut \& infin all'isole Molucche, dove nascono le Spetiere et la navigatione attorno il mondo: li nomi de gli auttori, et le nauigationi, et $i$ viaggi piu particolarmente si mostrano nel foglio seguente, Venezia.

RebufFAt, R.

(1973-74): “D’un portulan grec du XVI' siècle au Périple d'Hannon”, Karthago 17, 139-151. (1985-86): "Recherches sur le bassin du Sebou, II. Le Périple d'Hannon", Bulletin d'Archéologie Marocaine 16, 257-284.

(1988): "Voyage du Carthaginois Hannon, du Lixos à Cerné", Bulletin Archéologique du Comité des Travaux Historiques, N.S., Afrique du Nord 18B, 198-201.

(2001): "Pour une histoire événementielle du Maroc antique", [en] I ères Journées Nationales d'Archéologie et du Patrimoine (Rabat 1998), Rabat, vol. II, 25-48.

Rennell, J. (1830): The geographical system of Herodotus examined and explained by a comparison with those of other ancient authors and with modern geography, London ( $2^{\text {nd }}$ edition revised).

Roвiou, F. (1861): “Recherches nouvelles sur quelques périples d'Afrique dans l'antiquité. Néchao, Hannon, Eudoxe", Revue Archéologique $2^{a}$ S. 3, 191-215.

Roller, D. W. (2006): "The West African Voyage of Hanno the Carthaginian", The Ancient World 37/2, 115-125.

Rousseaux, M. (1949): “Hannon au Maroc”, Revue Africaine 93/420-421, 161-232.

SAGAZAN, L. M. DE (1936): “Un vieux problème d'histoire. Le périple d'Hannon et la colonie carthaginoise de Cerné”, La Revue Maritime 202, 460-487.

SAlle, G. DE LA (1980 [1404-19]): Le Canarien. Crónicas francesas de la conquista de Canarias. Texto $G$, Tenerife (edición de A. Cioranescu, en 3-67).

Santana, A. - Arcos, T.

(2002): "El conocimiento geográfico del Océano en la Antigüedad", Eres (ArqueologíaBioantropología) 10, 5-59.

(2009): "La descripción de África en Plinio (Nat. V y VI)", [en] Candau - González Ponce - Chávez (eds.), 2009, 347-360.

Santana, A. - Arcos, T. - Atoche, P. - Martín Culebras, J. (2002): El conocimiento geográfico de la costa noroccidental de África en Plinio: la posición de las Canarias (=Spudasmata 88), Hildesheim.

SAVAGE, T. S. (1847): "Notice of the external characters and habits of Troglodytes gorilla, a new species of orang from the Gaboon River", Boston Journal of Natural History 5, 417446.

SCHRADER, C.

(1987): Periplo de Hannón. Texto, traducción y léxico, Zaragoza.

(1990): "El mundo conocido y las tentativas de exploración. Los orígenes de la geografía descriptiva en Grecia”, [en] F. J. Gómez Espelosín - J. Gómez-Pantoja (eds.), Pautas para una seducción. Ideas y materiales para una nueva asignatura: Cultura Clásica, Madrid, 81-149. 
Schmit, $\mathrm{P}$.

(1968): “Connaissance des Îles Canaries dans l'Antiquité”, Latomus 27, 362-391.

(1974): "A la recherche du char des dieux", [en] R. Chevallier (éd.), Littérature grécoromaine et géographie historique. Mélanges offerts a Roger Dion (=Caesarodunum 9bis), Paris, 473-479.

SEdeño, A. (1978 [1507-1640]): Brebe resumen y historia muy verdadera de la conquista de Canaria, [en] F. Morales Padrón (ed.), Canarias: crónicas de su conquista, Sevilla-Las Palmas, 343-381.

SÉnAC, R. (1966): “Le périple du Carthaginois Hannon”, Bulletin de l'Association Guillaume Budé $4^{a} S .25 / 4,510-538$.

Simões de Paula, E. (1946): Marrocos e suas relações com a Ibéria na Antiguidade, São Paulo.

Simonides, K. (1864): The Periplus of Hannon, King of the Karchedonians, concerning the Lybian parts of the earth beyond the Pillars of Herakles, which he dedicated to Kronos, the greatest god, and to all the gods dwelling with him, London.

Tissot, Сн. (1877): "Recherches sur la géographie comparée de la Maurétanie Tingitane", Mémoires présentés para divers savants à l'Académie des Inscriptions et Belles-Lettres 9, 1 ére Série, 139-322.

Tlatli, S. E. (1978): La Carthage Punique. Étude urbaine, Paris.

TORRIANI, L. (1978 [1592]): Descripción e historia del reino de las Islas Canarias antes Afortunadas, con el parecer de sus fortificaciones, Tenerife (traducción, introducción y notas de A. Cioranescu).

Villaverde Vega, N. (2001): Tingitana en la antigüedad tardía (siglos III-VII): autoctonía y romanidad en el extremo occidente Mediterráneo (=Biblioteca Archaeologica Hispana 11), Madrid.

WARMINGTON, B. H.

(1960): Carthage, London.

(1969): Cartago, Barcelona.

Zurara, G. E. DA (1998 [1452-53]): Crónica del descubrimiento y conquista de Guinea (1448), La Laguna-La Orotava (edición de M. Hernández González - J. A. Delgado en A través del tiempo 16, 41-66). 